\title{
Permanent accumulated rotation of an offshore monopile wind turbine in sand during a storm
}

\author{
Wang, Shaofeng; Larsen, Torben Juul
}

Published in:

Ocean Engineering

Link to article, DOI:

10.1016/j.oceaneng.2019.106340

Publication date:

2019

Document Version

Peer reviewed version

Link back to DTU Orbit

Citation (APA):

Wang, S., \& Larsen, T. J. (2019). Permanent accumulated rotation of an offshore monopile wind turbine in sand during a storm. Ocean Engineering, 188, [106340]. https://doi.org/10.1016/j.oceaneng.2019.106340

\section{General rights}

Copyright and moral rights for the publications made accessible in the public portal are retained by the authors and/or other copyright owners and it is a condition of accessing publications that users recognise and abide by the legal requirements associated with these rights.

- Users may download and print one copy of any publication from the public portal for the purpose of private study or research.

- You may not further distribute the material or use it for any profit-making activity or commercial gain

- You may freely distribute the URL identifying the publication in the public portal

If you believe that this document breaches copyright please contact us providing details, and we will remove access to the work immediately and investigate your claim. 


\title{
Permanent accumulated rotation of an offshore monopile wind turbine in sand during a storm
}

\author{
Shaofeng Wang ${ }^{\mathrm{a}, *}$, Torben Juul Larsen ${ }^{\mathrm{a}}$ \\ ${ }^{a}$ Department of Wind Energy, Technical University of Denmark, Frederiksborgvej 399, 4000 Roskilde, \\ Denmark
}

\begin{abstract}
Offshore wind turbines exposed to storm situations are subjected to static and dynamic loads from the same direction over a considerable period of time. Such cyclic loading can potentially result in soil degradation, leading to an undesired permanent rotation of the wind turbine. This paper presents a workflow to predict the permanent accumulated rotation of an offshore monopile wind turbine in sand during an extreme storm event incorporating the use of fully nonlinear irregular waves versus linear waves in current practice. The fully nonlinear irregular waves are realized from a potential flow solver OceanWave3D previously validated at up to near-breaking wave conditions. Given the wave kinematics, the aerohydro-elastic code HAWC2 is used to calculate horizontal loading and bending moment acting on the embedded pile head. The irregular load series is then decomposed into a set of constant-amplitude load parcels using rainflow counting. Eventually, the permanent accumulated rotation is predicated using the method proposed by LeBlanc et al. (2010b) with Miner's rule-based superposition. In this paper, a case study of the DTU 10MW wind turbine supported by a monopile at $33 \mathrm{~m}$ water depth in sand is presented, where the pile is primarily laterally loaded. The simulation results suggest the importance of taking accumulated rotation into design. The permanent accumulated rotation is primarily decided by soil capacity, loading characteristics and pre-loading history. Furthermore, the results show that wave nonlinearity has only limited influence on the permanent accumulated rotation.
\end{abstract}

Keywords: monopile, cyclic loading, permanent accumulated rotation, fully nonlinear irregular waves, sand

\footnotetext{
${ }^{*}$ Corresponding author

Email address: shfe@dtu.dk (Shaofeng Wang)
} 


\begin{tabular}{|c|c|c|c|}
\hline \multicolumn{2}{|c|}{ Nomenclature } & $H$ & Horizontal load \\
\hline$\beta$ & Wave spectrum shape factor & $h$ & Water depth \\
\hline$\Delta \omega$ & Wave frequency bandwidth & $H_{S}$ & Significant wave height \\
\hline$\dot{u}_{r e l}$ & Relative water particle acceleration & $k$ & Initial modulus of subgrade reaction \\
\hline$\eta$ & Wave surface elevation & $L$ & Wave length \\
\hline$\gamma$ & Peak enhancement factor & $L_{e m}$ & Embedded pile length \\
\hline$\gamma^{\prime}$ & Soil submerged unit weight & $M$ & Bending moment \\
\hline$\omega$ & Wave frequency & $M_{R}$ & Ultimate soil moment capacity \\
\hline $\begin{array}{l}\omega_{p} \\
\phi\end{array}$ & $\begin{array}{l}\text { Peak wave frequency } \\
\text { Wave phase }\end{array}$ & $M_{\max }$ & Maximum moment of cyclic loads \\
\hline$\phi^{\prime}$ & Soil friction angle & $M_{\min }$ & Minimum moment of cyclic loads \\
\hline$\rho$ & Water density & $N$ & Number of cyclic loads \\
\hline$\theta$ & Accumulated rotation & $p$ & $\begin{array}{l}\text { Lateral soil reaction force per unit } \\
\text { length }\end{array}$ \\
\hline$\theta_{s}$ & Static rotation & $p_{u}$ & Ultimate resistance of the sand \\
\hline $\begin{array}{l}\xi_{b} \\
\xi_{c}\end{array}$ & $\begin{array}{l}\text { Cyclic load intensity parameter } \\
\text { Cyclic load profile parameter }\end{array}$ & $T_{b}$ & $\begin{array}{l}\text { Rotation accumulation magnitude } \\
\text { fuction }\end{array}$ \\
\hline$A$ & $\begin{array}{l}\text { Static or cyclic loading condition pa- } \\
\text { rameter }\end{array}$ & $T_{c}$ & Rotation accumulation profile fuction \\
\hline$A$ & Wave amplitude & $T_{P}$ & Peak wave period \\
\hline$A_{i}$ & Internal cross sectional area & $u$ & Water particle velocity \\
\hline$A_{s}$ & Sand density coefficient & $u_{r e l}$ & Relative water particle velocity \\
\hline$A_{t}$ & Total cross sectional area & $V_{g}$ & Wave group velocity \\
\hline$C_{a}$ & Added mass coefficient & $w s p$ & Mean wind speed \\
\hline$C_{d}$ & Drag coefficient & $y$ & Lateral soil deflection \\
\hline$C_{1,2,3}$ & Soil lateral resistance coefficients & $z$ & Soil depth \\
\hline$D$ & Pile diameter & OWT & Offshore wind turbine \\
\hline$e$ & Load eccentricity & SLS & Serviceability limit state \\
\hline
\end{tabular}




\section{Introduction}

Offshore wind power is currently gaining an increased popularity around the world as a promising source of renewable energy, especially in a number of European countries such as Denmark, Germany, the United Kingdom and the Netherlands. In order to make offshore 5 wind energy more competitive with traditional energy sources, optimization of foundation designs is of high importance as the foundation can account for up to $35 \%$ of the total installed cost (Byrne \& Houlsby, 2003). Up to now, monopile is the dominant foundation with $87 \%$ of the market share as it is a more cost effective solution with cheaper fabrication and installation cost (WindEurope, 2018). The loading acting on offshore wind turbines (OWTs) is highly cyclic as a result of the stochastic nature of the environmental conditions, which might lead to possible softening/hardening of the surrounding soil and eventually lead to permanent accumulated rotation or lateral displacement at mudline (Zaaijer, 2006; Bhattacharya et al., 2013, Lombardi et al., 2013, Damgaard et al., 2014; Carswell et al., 2016). In terms of the serviceability limit state (SLS) assessment for monopile OWTs, the accumulated rotation prediction is typically a critical aspect as opposed to the prediction of displacement (Arany et al., 2017). DNV (2014) suggests that OWT monopiles are typically designed to not exceed the tolerance of $0.5^{\circ}$ for the total rotation at mudline where the installation tolerance at seabed is $0.25^{\circ}$ and the limit for permanent accumulated rotation becomes $0.25^{\circ}$. Therefore, the permanent accumulated rotation due to cyclic loading should be a key consideration to achieve a safe design of the OWT, and it has been a subject of intense study.

Extensive attentions have been paid on incorporating cyclic loading effect into numerical simulations to model the lateral response of piles since the development of the so-called $p-y$ curves. Reese et al. (1974) suggested that the soil reaction $p$ should be reduced by a constant factor to account for the cyclic effect, which has been advocated in current design standards such as API (2007) and DNV (2014). The model is independent of the cyclic load characteristics and the number of cycles, hereby it cannot capture the pile behavior cycle by cycle. Little \& Briaud (1988) further addressed this issue by introducing the idea of degradation index as a function of the number of cycles. Following this work, Long \& Vanneste (1994) refined the degradation index to cover a wide range of soil densities, load conditions, pile types and materials. Alternatively, a versatile dynamic nonlinear Winkler foundation model was developed by Allotey \& El Naggar (2008) to account for cyclic soil degradation. Although the current $p-y$ approach has gained broad recognition, the accuracy and validity of these $p-y$ curves, when applied to the soil-pile response of a large diameter monopile, are questionable (Kallehave et al., 2015). As an alternative to the $p-y$ approach, $3 \mathrm{D}$ finite element model is widely used for modeling complex 3D soil-structure interaction problems. Cuéllar et al. (2014) and Corciulo et al. (2017) used a comprehensive 3D finite element model with cyclic hydro-mechanical soil coupling to capture the transit response subject to an extreme loading. In principle these models developed with implicit concept can simulate the pile behavior under the loading cycle by cycle, but they are restricted to limited number of cycles considering the expensive computation time. Alternatively, an explicit degradation stiffness model was proposed by Achmus et al. (2009) based on a 
combination of a finite element simulation of the pile-soil interaction and an evaluation of drained cyclic triaxial tests. It was further reported by Achmus et al. (2010) that the results using this model compare well with scaled pile test results. Although the 3D finite element model is the most accurate way to simulate soil-structure interaction, it is impractical to use in the design optimization stage regarding the cost of great computation efforts.

In alignment with the numerical modeling, a number of experimental tests have been conducted to investigate the cyclic behavior of laterally loaded piles and several empirical formulations have been derived by fitting the recorded measurements. LeBlanc et al. (2010b) performed small-scaled laboratory tests on stiff pile subject to long term cyclic loading, and developed an accumulation model based on a power law. The model is in agreement with the findings from Little \& Briaud (1988), Long \& Vanneste (1994), Klinkvort \& Hededal (2013), Li et al. (2015) and Truong et al. (2018). In addition, logarithmic expressions have also been proposed by Hettler (1981), Lin \& Liao (1999) and Achmus et al. (2009). These formulations simulate the long term cyclic soil response as a function of the cyclic load characteristics and the number of cycles based on an explicit concept, in contrast to an implicit concept that the soil response is simulated cycle by cycle. Therefore, they are believed to be efficient in practical applications to monopile designs. Furthermore, it is found out that the accumulated rotation could be better approximated by the power law in contrast to the logarithmic formulation (Abadie, 2015; Barari et al., 2017; Yang et al. 2018). Hereby, the model proposed by LeBlanc et al. (2010b) is used in this study.

Current models are primarily derived from scaled pile tests using a wide range of regular cyclic loadings from extreme one-way loading to extreme two-way loading, which are unrealistic loading situation experienced by an OWT. To the author's knowledge, the study on cyclic response of a realistic OWT, exposed to stochastic environmental conditions at least in a single storm (DNV, 2014), is rare and needs further investigation. Therefore, the aim of this paper is to investigate the permanent accumulated rotation experienced by a realistic OWT during an extreme storm. For this purpose, a design framework, which enables the designer to calculate the accumulation of monopile rotation in a realistic and practical way, is established. In this paper, the DTU $10 \mathrm{MW}$ wind turbine supported by a monopile in sand sited in $33 \mathrm{~m}$ water depth is investigated. A 39-hour storm with 50-year return period is adopted in this study (NORSOK N-003, 2007). In addition, the results from LeBlanc et al. (2010a) indicated that largest load cycles, although very few in number, have a significantly higher impact on the permanent accumulated rotation than small load with thousands of cycles, and it has been reported from a range of available literature that loads predicted from nonlinear wave models are often larger than those predicted from linear wave theory (Agarwal \& Manuel, 2011; Marino et al., 2015; Schløer et al., 2016, Wang \& Larsen, 2017). With these findings in mind, this paper also investigates the effect of using fully nonlinear irregular waves on predicting the permanent accumulated rotation.

This paper starts with a description of the research methodology used in this study, with detailed elaboration on wave modeling, aero-elastic simulations and cyclic accumulation analysis. Afterwards, a case study of the DTU 10MW OWT is presented and the results are summarized and discussed. Finally, the conclusions are given. 


\section{Research methodology}

In principle, the research methodology is based on the explicit concept, which means that the soil deformation is not simulated cycle by cycle, instead it is calculated using a post-processing step without considering the interaction between soil deformation and structural responses. The research methodology is schematically shown in Figure 1 through three steps: wave realizations, aero-elastic simulations and cyclic accumulation analysis. Regarding wave realizations, fully nonlinear irregular waves are realized using a validated potential wave solver OceanWave3D (Engsig-Karup et al., 2009), in addition to linear wave theory widely used in current practice. Consequently, wave kinematics associated with the linear and nonlinear wave realizations are incorporated into aero-elastic calculations using HAWC2 (Larsen \& Hansen, 2015). The horizontal loading and bending moment acting on the embedded pile head are obtained and then converted into constant-amplitude cyclic load parcels using the rainflow counting method (Khoa \& Jostad, 2017) for the cyclic accumulation analysis. In order to perform cyclic accumulation analysis, static moment-rotation relation of the pile is firstly established using nonlinear $p-y$ curves of sand recommended by API (2007) assuming rigid behavior of the embedded pile. Finally, the model proposed by LeBlanc et al. (2010b) with Miner's rule-based superposition is used for prediction of the permanent accumulated rotation exposed to extreme storms.

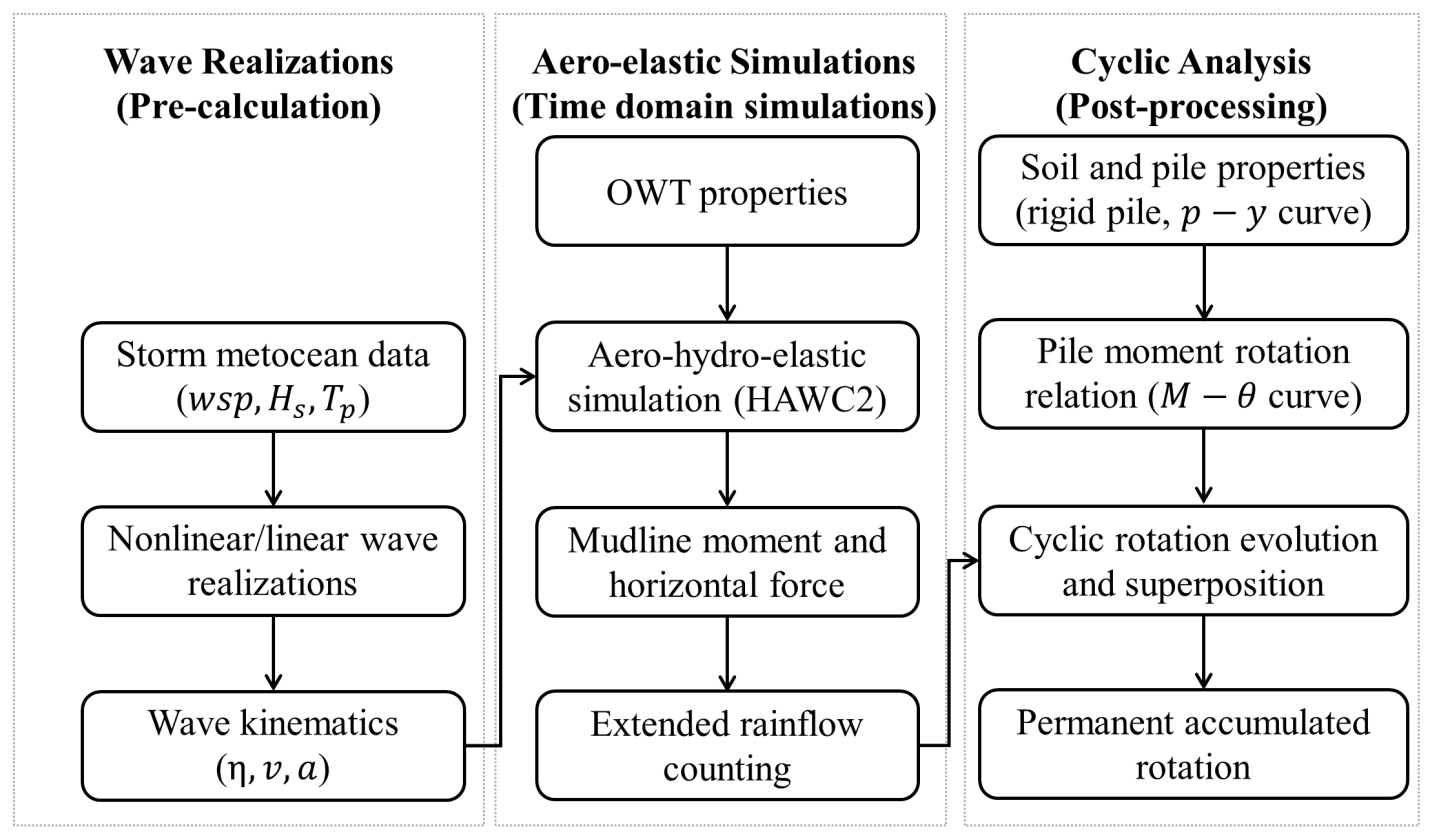

Figure 1: Flowchart of the research methodology for prediction of offshore monopile permanent accumulated rotation exposed to an extreme storm event. 


\subsection{Irregular wave realizations}

With respect to a realistic sea, the wave fields vary continuously over space and time in an irregular manner. Hereby, a realistic sea can not be represented by a deterministic regular wave, and it should be treated as a stochastic process.

Linear wave theory is the most common way to represent Gaussian stochastic ocean waves and is widely used in aero-elastic simulations for dynamic load analysis of OWTs. A wave spectrum, typically a Jonswap spectrum (Hasselmann et al., 1973), is the starting point for generating linear irregular waves. The Jonswap spectrum is defined by the following equations:

$$
\begin{gathered}
S(\omega)=(1-0.287 \ln (\gamma)) \cdot \frac{5}{16} H_{S}^{2} \omega_{p}^{4} \omega^{-5} \exp \left(-\beta \frac{\omega_{p}^{4}}{\omega^{4}}\right) \gamma^{a} \\
a=\exp \left(-\frac{\left(\omega-\omega_{p}\right)^{2}}{2 \omega_{p}^{2} \sigma^{2}}\right) \\
\sigma= \begin{cases}0.07 & \omega \leq \omega_{p} \\
0.09 & \omega>\omega_{p}\end{cases}
\end{gathered}
$$

where $\beta=\frac{5}{4}, \gamma=3.3, H_{S}$ is the significant wave height, $\omega$ is the wave frequency and $\omega_{p}$ is the peak wave frequency.

A stochastic wave elevation time series $\eta(t)$ from the spectrum can be generated using the following linear superposition:

$$
\begin{gathered}
\eta(t)=\sum_{i} A_{i} \cos \left(\omega_{i} t+\phi_{i}\right) \\
A_{i}=\sqrt{2 S\left(\omega_{i}\right) \Delta \omega} \\
\phi_{i}=\operatorname{rand}(0,2 \pi)
\end{gathered}
$$

where $A_{i}$ is the $i$ th wave amplitude, $\omega_{i}$ is the $i$ th wave frequency, $\Delta \omega$ is wave frequency bandwidth and $\phi_{i}$ is the $i$ th random wave phase.

In terms of the nonlinear irregular wave realizations, the fully nonlinear potential flow solver OceanWave3D, developed by Engsig-Karup et al. (2009), is applied, which solves the 3D Laplace equation for the velocity potential, the free surface elevation up to the point of breaking with nonlinear boundary conditions at the free surface and the impermeability condition at the seabed. The interested reader is referred to Engsig-Karup et al. (2009) for further information.

\subsection{Load simulation and transformation}

\subsubsection{Aero-hydro-elastic simulations}

DTU Wind Energy developed aero-elastic code HAWC2 (Larsen \& Hansen, 2015; Larsen et al., 2014) is used to perform all the aero-hydro-elastic simulations based on multibody 
formulation with floating frame. For OWT exposed to a storm, the wind turbine is at a standstill condition by setting rotational speed as zero and pitch angle to a feathered position. In addition, control is not active when the turbine is at a standstill condition. Therefore, the aerodynamic loads are negligible, and the hydrodynamic loads and wave-excited structural vibrations dominate the loads at the monopile mudline. Regarding hydrodynamic loads, the Morison equation is used with three force terms: the Froud-Krylov force, the water added mass and the drag force. The hydrodynamic loading per unit length of flooded members is written as:

$$
f=\frac{1}{2} C_{d} \rho D u_{r e l}\left|u_{r e l}\right|+\rho\left(A_{t}-A_{i}\right) \dot{u}+\rho\left(C_{a} A_{t}+A_{i}\right) \dot{u}_{r e l}
$$

where $C_{d}$ and $C_{a}$ are drag and added mass coefficients respectively. For monopiles, the wave force is dominated by inertial force where the theoretical value of added mass coefficient $C_{a}$ is 1 . In addition, the value of $C_{d}$ is also chosen as 1 considering a rough structure due to corrosion and marine growth. $u$ is the water particle velocity, and $u_{r e l}, \dot{u}_{r e l}$ represent the relative velocity and acceleration respectively. $\rho$ is the water density and $D$ is the diameter of slender piles. $A_{t}$ and $A_{i}$ are the total and internal reference cross sectional areas. The internal area, $A_{i}$, accounts for water mass inside the cylinder to include its inertial force.

\subsubsection{Transform irregular loading to cyclic loading}

The typical load series used for monopile geo-technical design consist of the simultaneous lateral force $H$ and bending moment $M$. The combined load pairs $(H, M)$ can be represented by a single loading $M$ or $H$ using the deterministic relation $M=H \cdot e$, where $e$ is called as load eccentricity representing the average correlation coefficient between the bending moment $M$ and the lateral force $H$. Thus, the moment time series can be used as the design load series, which consists of a considerable number of load cycles with highly irregular load amplitudes. It requires a great deal of computation effort for direct modeling in time domain. For the sake of convenience, the irregular load time series are usually rearranged into the so-called load parcels, which have been widely addressed in practical design (Andersen, 2015; Carswell et al., 2016). For each load parcel, it is a $N$ cycles constant-amplitude load series bounded by the maximum and minimum moment, $M_{\max }$ and $M_{\min }$ respectively in this study. The transformation is performed with either the rainflow counting method (Matsuishi \& Endo, 1968) or the method developed at Norwegian Geotechnical Institute (NGI) (Andersen, 2015). In the case of the NGI method, pore pressure accumulation is considered for determining the equivalent number of cycles, which is likely more accurate. However, the computational expense and complexity of the model are limiting factors for its practical use (Carswell et al. 2016). Therefore, the rainflow counting method is used in this study to perform the transformation. The procedure is illustrated in Figure 2.

For each load parcel, the cyclic loading is characterized in terms of two non-dimensional parameters, $\xi_{b}$ and $\xi_{c}$, determined by the ultimate soil capacity $M_{R}$ (LeBlanc et al., 2010a b).

$$
\xi_{b}=\frac{M_{\max }}{M_{R}}
$$




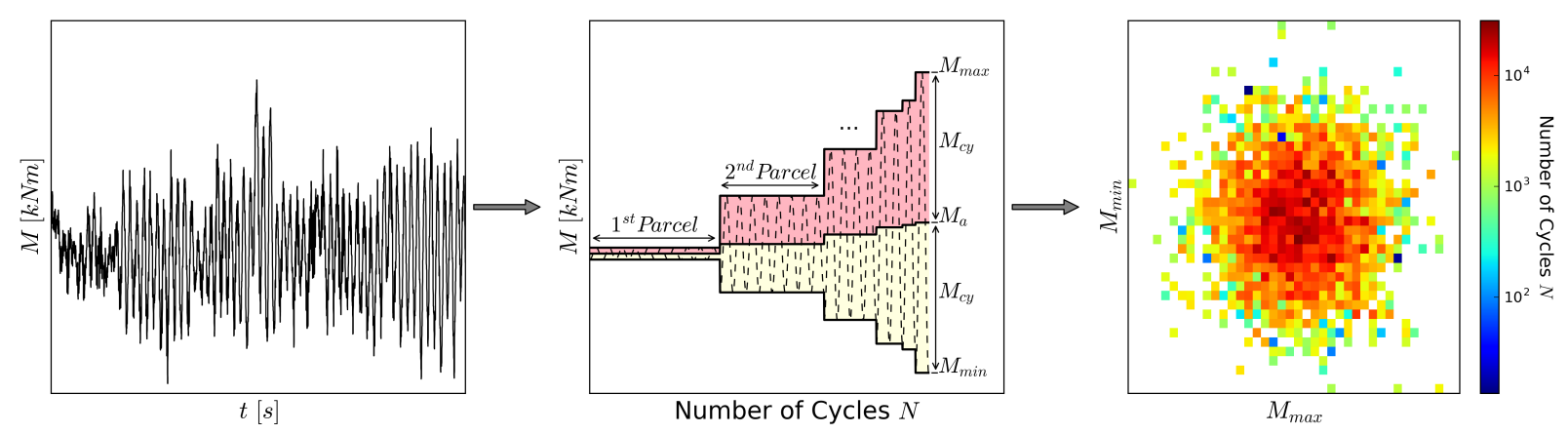

Figure 2: Illustration of transforming an irregular load series into load parcels of constant-amplitude cyclic loading using the rainflow counting method (modified from Khoa \& Jostad (2017)).

$$
\xi_{c}=\frac{M_{\min }}{M_{\max }}
$$

where $\xi_{b}$ is a measure of the load magnitude normalized with the static moment capacity within the range of 0 to $1 . \xi_{c}$ quantifies the characteristics of the cyclic loading bounded with -1 to 1 , which takes the value 1 for a static loading, 0 for one-way loading and -1 for two-way loading.

\subsection{Permanent accumulated rotation analysis}

\subsubsection{API $p-y$ curves for sand}

API (2007) standard recommends the use of Reese's sand $p-y$ curves (Reese et al., 1974) for soil lateral resistance in case where no more specific information is available. In general, $p-y$ curves are nonlinear and a function of depth, soil type, pile dimensions and properties. The curves for sand are described with depth $z$ as:

$$
p=A p_{u} \tanh \left(\frac{k z}{A p_{u}} y\right)
$$

where $p_{u}$ is the ultimate resistance of the sand at depth $z$, the factor $A$ accounts for cyclic or static loading condition, which is chosen as 0.9 at all depths as the loading is cyclic. $k$ is the initial modulus of subgrade reaction and $k z$ is called subgrade modulus. $y$ is the soil lateral deflection. The schematic $p-y$ curve comprises an initial portion of a straight line with a constant slope $k z$, followed by a hyperbolic curve until it reaches the soil resistance $p_{u}$, after which the $p-y$ curve becomes flat and extends to a certain extent (Jia, 2018), which is depicted in Figure 3 at different depths for sand.

The initial modulus of subgrade reaction $k$, which is also called coefficient of subgrade reaction, is approximated as (Terzaghi, 1955):

$$
k=\frac{A_{s} \gamma^{\prime}}{1.35}
$$



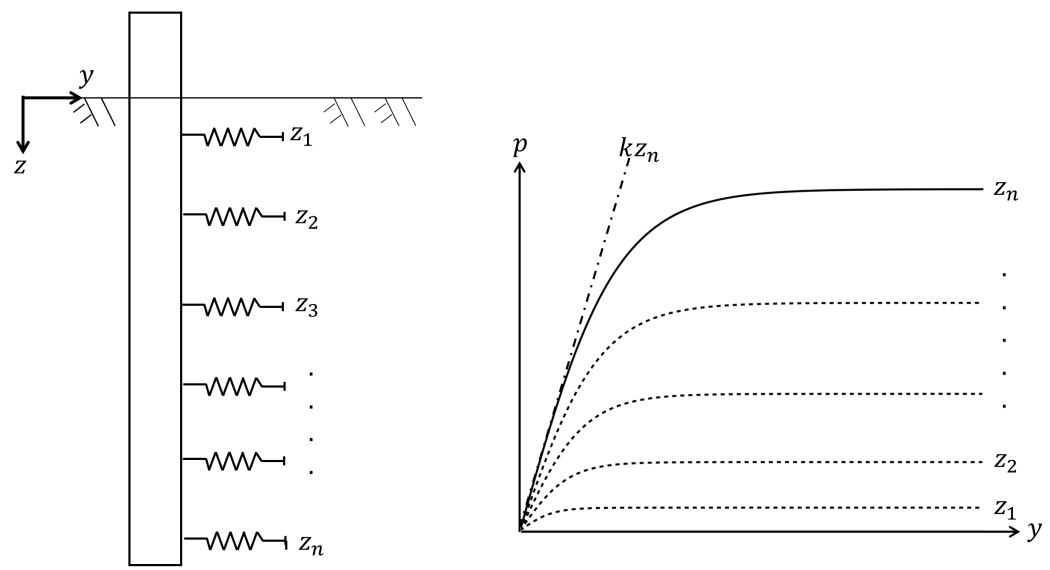

Figure 3: Schematic representation of nonlinear $p-y$ curves at different depths for the geological condition of sand.

where $\gamma^{\prime}$ is the submerged unit weight, and $A_{s}$ is a coefficient which depends only on sand density, which is chosen as 900 for medium dense sand leading to a value of $6000 \mathrm{kN} / \mathrm{m}^{3}$ for $k$.

The ultimate lateral soil resistance for sand has been found to vary with depth. Based on the recommendations from API (2007), the ultimate lateral bearing capacity at shallow soil depth can be calculated as:

$$
p_{u s}=\left(C_{1} z+C_{2} D\right) \gamma^{\prime} z
$$

at deeper depth, the ultimate lateral bearing capacity can be calculated as:

$$
p_{u d}=C_{3} D \gamma^{\prime} z
$$

where $C_{1}, C_{2}, C_{3}$ are the lateral resistance coefficients as a function of the effective internal friction angle of sand. $\gamma^{\prime}$ is the effective density of soil and $D$ is the pile diameter.

In practical design, at a given depth the equation giving the smallest value of $p_{u}$ should be used as the ultimate lateral resistance:

$$
p_{u}=\min \left(p_{u s}, p_{u d}\right)
$$

\subsubsection{Cyclic accumulation model}

A number of experimental investigations have been performed and several models have been proposed (Niemunis et al., 2005; LeBlanc et al., 2010b; Klinkvort \& Hededal, 2013; Wichtmann \& Triantafyllidis, 2017). The cyclic accumulation process and its relation with a moment rotation curve are illustrated in Figure 4. The static moment-rotation curve is used to determine the rotation in the first loading cycle, similar to a static pushover analysis. The most commonly used cyclic accumulation models in the literature for embedded pile rotation subject to cyclic loading are primarily in exponential or logarithmic type, some of which are summarized in Table 1 


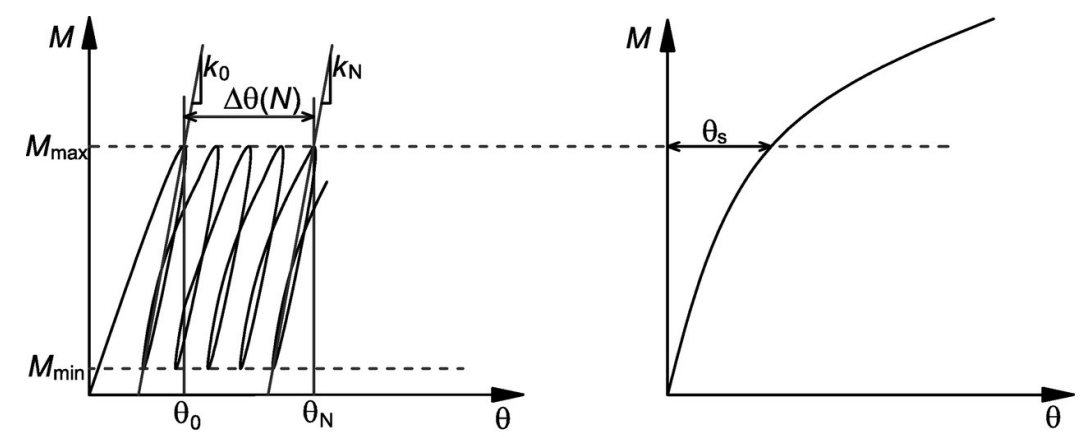

Figure 4: Illustration of cyclic accumulation for the rotation $\theta_{N}$ after cyclic loading with number of cycles $N$ (reproduced from LeBlanc et al. $(2010 \mathrm{~b})$ ). The value for $\theta_{0}$ can be replaced by $\theta_{s}$ corresponding to the static rotation.

Table 1: Cyclic accumulation models proposed by different researchers for long-term accumulated rotation estimation of lateral loaded pile ( $\theta$ is the accumulated rotation after $N$ cycles, $\theta_{s}$ is the rotation that would occur in a static test, the other parameters are not elaborated here).

\begin{tabular}{ll}
\hline Reference & Evolution Model \\
\hline Hettler (1981) & $\theta=\theta_{s}(1+t \ln N)$ \\
\hline \hline Little \& Briaud (1988) & $\theta=\theta_{s} N^{m}$ \\
\hline \hline Achmus et al. & $\theta=\theta_{s} N^{b_{1} X^{b_{2}}}$ \\
\hline LeBlanc et al. (2009) & $\theta=\theta_{s}\left(1+T_{b} T_{c} N^{0.31}\right)$ \\
\hline Klinkvort \& Hededal & $\theta=\theta_{s} N^{T_{b} T_{c}}$ \\
\hline
\end{tabular}

In this paper, the model proposed by LeBlanc et al. (2010b) is applied for predicating the cyclically accumulated rotation in sand, which is built up on the model from Little \& Briaud (1988) following a power function written as:

$$
\begin{gathered}
\theta=\theta_{s}+\Delta \theta(N) \\
\Delta \theta(N)=T_{b} T_{c} N^{0.31} \theta_{s}
\end{gathered}
$$

where $\theta$ is the maximum rotation after a load parcel with $N$ cycles and $\theta_{s}$ is the static rotation responding to the load magnitude $M_{\max } . T_{b}$ and $T_{c}$ are dimensionless coefficients primarily depending on the load characteristics $\xi_{b}$ and $\xi_{c}$. $T_{b}$ is also affected by the relative density of sand, and the value of $38 \%$ is assumed in this study, the same data as used in LeBlanc et al. (2010b). The functions of $T_{b}, T_{c}$ are determined by a series of centrifuge tests (LeBlanc et al., 2010b) and subsequently linearly approximated by Arany et al. (2017).

$$
T_{b}\left(\xi_{b}\right)= \begin{cases}0 & 0.0 \leq \xi_{b} \leq 0.051 \\ 0.4238 \xi_{b}-0.0217 & 0.051<\xi_{b} \leq 1.0\end{cases}
$$




$$
T_{c}\left(\xi_{c}\right)= \begin{cases}13.71 \xi_{c}+13.71 & -1 \leq \xi_{c}<-0.65 \\ -5.54 \xi_{c}+1.2 & -0.65 \leq \xi_{c}<0 \\ -1.2 \xi_{c}+1.2 & 0 \leq \xi_{c} \leq 1\end{cases}
$$

The function $T_{b}$ denotes whether the yield strength is breached, which shows a linear dependence of the load magnitude $\xi_{b}$. Moreover, $T_{b}$ has a value of 0 under cyclic loading with a small magnitude $\xi_{b} \leq 0.051$, which implies that no accumulation of rotation would occur as the pile-soil interaction is elastic and reversible in this condition. The function $T_{c}$ represents the influence of load amplitude, which follows a third-step established linear relation ensuring that $\Delta \theta=0$ for $\xi_{c}=1$ corresponding to a static loading. It is also found that the maximum value of $T_{c}$ is reached at $\xi_{c}=-0.65$. This observation disagrees with the conclusion from Klinkvort \& Hededal (2013) that one-way loading, corresponding to $\xi_{c}=0$, is the most critical load scenario. Figure 5 shows the power function relation between the cyclically accumulated rotation $\theta$ with number of cycles $N$ for a given load characteristics. One can also observe a significant decrease of accumulation rate with increasing number of cycles. Such a decrease is possibly a result of sand densification where the near-field soil is stiffened under cyclic loading (Niemunis et al., 2005; LeBlanc et al., 2010b; Bhattacharya et al., 2013, Klinkvort \& Hededal, 2013; Wichtmann \& Triantafyllidis, 2017).
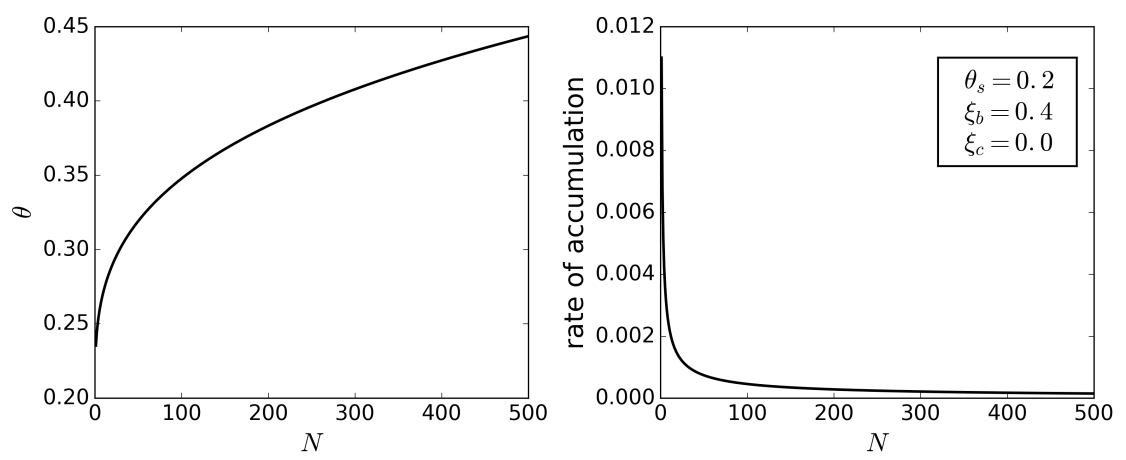

Figure 5: Illustration of cyclically accumulated rotation and its corresponding accumulation rate as a function of the number of cycles.

\subsubsection{Miner's rule-based rotation superposition}

The permanent accumulated rotation subject to variable cyclic loadings can be superposed based on a relation similar to Miner's rule (LeBlanc et al., 2010a). The assumption using Miner's rule is that the damage is independent of loading consequence, which has been validated against experimental data (LeBlanc et al., 2010a; Li et al., 2015; Wichtmann \& Triantafyllidis, 2017). For example, the accumulated rotation $\theta_{a}$ for $N_{a}$ cycles of load parcel $a$ is calculated as:

$$
\Delta \theta_{a}=\left(\theta_{s} T_{b} T_{c}\right)_{a} N_{a}^{0.31}
$$


Alternatively, the accumulated rotation $\Delta \theta_{a}$ can be represented by $N_{b}^{0}$ cycles for load parcel $b$ and the equivalent number of cycles $N_{b}^{0}$ can be calculated as:

$$
N_{b}^{0}=\left(\frac{\Delta \theta_{a}}{\left(\theta_{s} T_{b} T_{c}\right)_{b}}\right)^{1 / 0.31}
$$

Therefore, the resulting accumulated rotation for load parcel $b$ with $N_{b}$ cycles following load parcel $a$ with $N_{a}$ cycles can be evaluated as:

$$
\Delta \theta_{b}=\left(\theta_{s} T_{b} T_{c}\right)_{b}\left(N_{b}^{0}+N_{b}\right)^{0.31}
$$

And the permanent accumulated rotation under cyclic load parcel $(a, b)$ according to Eq. (15) is written as:

$$
\theta_{b}=\Delta \theta_{b}+\max \left(\theta_{s, a}, \theta_{s, b}\right)
$$

With this approach, more load parcels with variable cyclic loading characteristics can be applied while maintaining the rotation accumulated in previous loading history. The procedure for prediction of accumulated pile rotation subjected to variable cyclic loadings is further illustrated in Figure 6 with three load parcels. After $N_{1}$ cycles for the first load parcel, a rotation $\theta_{1}$ is generated, which is equivalent with $N_{2}^{0}$ cycles for the second load parcel. The cyclically accumulated rotation for second load parcel with $N_{2}$ cycles then starts from the point $\left(N_{2}^{0}, \theta_{1}\right)$ and reach the point $\left(N_{2}^{0}+N_{2}, \theta_{2}\right)$. In a similar manner the procedure is applied to the third load parcel with $N_{3}$ cycles leading to the final rotation at $\theta_{3}$. The procedure can be applied to more load parcels with random sorting order as the accumulated rotation is independent of the loading consequence.

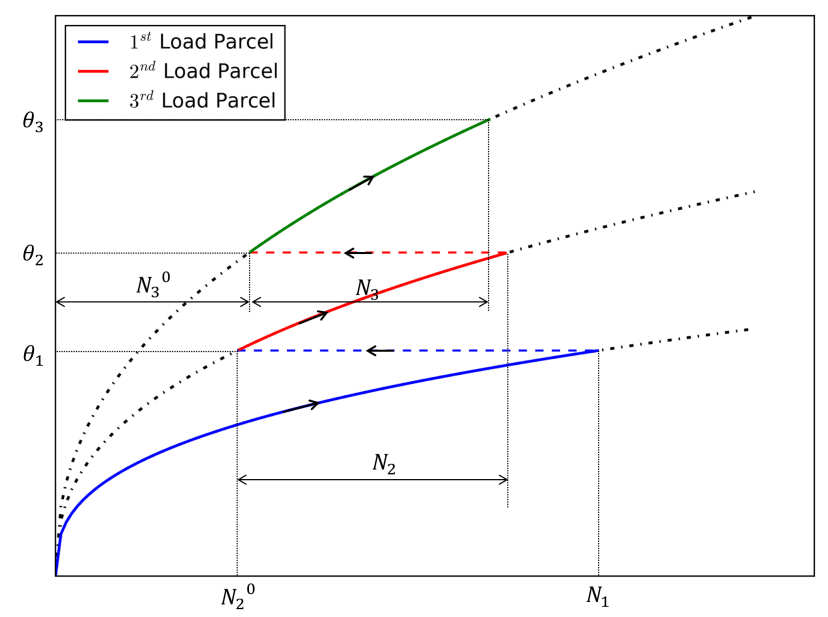

Figure 6: Illustration of accumulated pile rotation subjected to variable cyclic loadings following a order of $1-2-3$.

The phenomenon of superposition subject to variable cyclic loadings demonstrates that the cyclic accumulation rate is highly dependent on the initial rotation accumulated from the previous loading history. 


\section{Application to the DTU 10MW offshore turbine}

\subsection{Offshore wind turbine structure}

The DTU 10MW reference wind turbine (Bak et al., 2013), which is a conventional horizontal axis, three bladed and upwind type turbine on a tubular tower, supported by a large monopile sited in $33 \mathrm{~m}$ water depth is studied, shown in Figure 7. It is considered to be representative for the latest multi-MW wind turbine on the market. The monopile is designed as $7.5 \mathrm{~m}$ wide, $85 \mathrm{~mm}$ thick and the embedded lengths below seabed are assumed to be 30, 35 and $40 \mathrm{~m}$. Key design properties are summarized in Table 2. It is remarkable that this model is assumed to be fixed at seabed with a rigid foundation and the wind turbine locked during the storm. The load transfer is primarily through lateral soil structure interaction where the horizontal loading and bending moment acting on the surrounding soil are substantial compared to the vertical loading also shown in Figure 7.

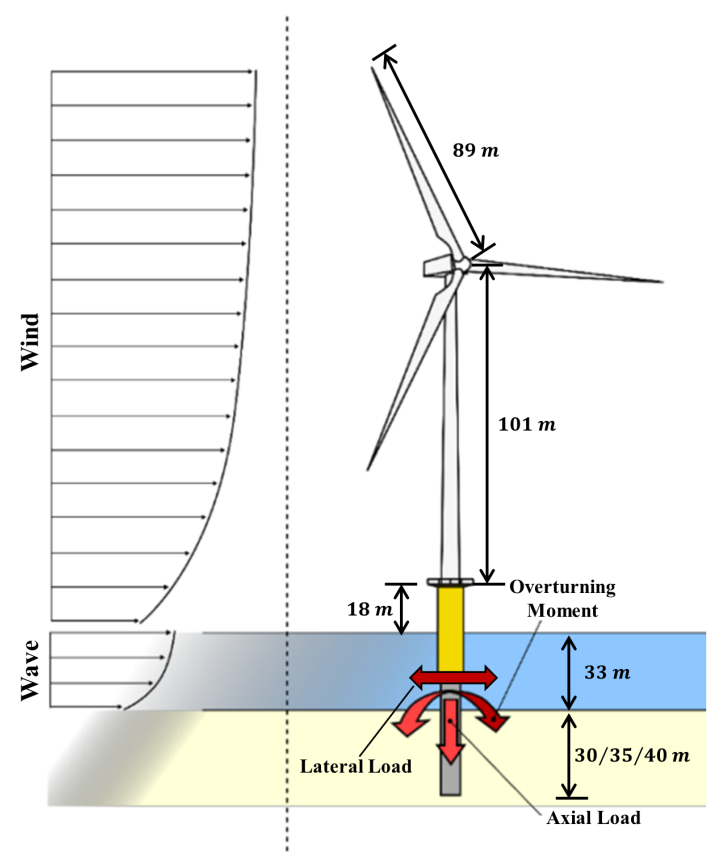

Figure 7: The DTU 10MW wind turbine supported by a monopile sited in $33 \mathrm{~m}$ water depth. The pile embedded lengths below seabed are 30,35 and $40 \mathrm{~m}$ and the load transfer mechanism is also demonstrated (modified from Bhattacharya et al. (2012)). 
Table 2: Key design properties of the DTU 10MW reference wind turbine supported by a large monopile sited in $h=33 \mathrm{~m}$ (Nat.Freq means natural frequency and damping is given in the format of logarithmic decrement).

\begin{tabular}{ll}
\hline Parameters & Values \\
\hline Rated power & $10 \mathrm{MW}$ \\
Rated wind speed & $11.4 \mathrm{~m} / \mathrm{s}$ \\
Cut-in, cut-out speed & $4 \mathrm{~m} / \mathrm{s}, 26 \mathrm{~m} / \mathrm{s}$ \\
Controller & Variable-speed pitch control \\
Rotor speed & $6 \mathrm{rpm}-9.6 \mathrm{rpm}$ \\
Rotor diameter & $178.3 \mathrm{~m}$ \\
Hub height & $119 \mathrm{~m}$ above MSL \\
Water depth & $33 \mathrm{~m}$ \\
Embedded pile length & $30,35,40 \mathrm{~m}$ \\
Monopile diameter & $7.5 \mathrm{~m}$ \\
Monopile thickness & $0.085 \mathrm{~m}$ \\
$1^{\text {st }}$ Nat.Freq, Damping & $0.22 \mathrm{~Hz}, 5.8 \%$ \\
$2^{\text {nd }}$ Nat.Freq, Damping & $0.23 \mathrm{~Hz}, 5.9 \%$ \\
\hline
\end{tabular}




\subsection{Bathymetry and storm profile}

A representative seabed profile is used in this paper with a slope around 1:100, similar to 215 Schløer et al. (2016), depicted in Figure 8. The total distance of the wave domain is 11500 $\mathrm{m}$ between water depth $h=100 \mathrm{~m}$ and $h=30 \mathrm{~m}$. The monopile-supported OWT is sited in $h=33 \mathrm{~m}$ water depth. The waves in the storm event are generated in $100 \mathrm{~m}$ water depth and move up over the sloping seabed until $30 \mathrm{~m}$ water depth.

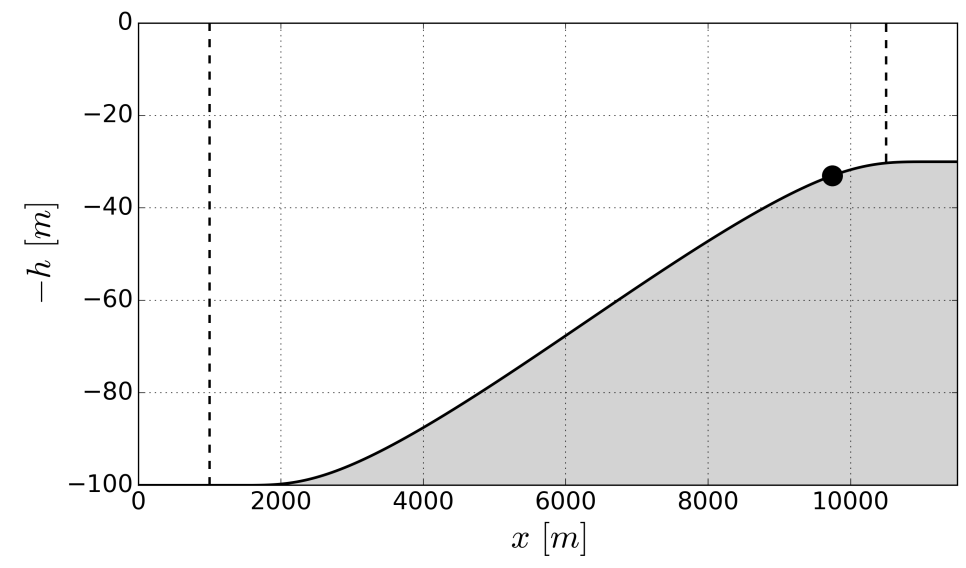

Figure 8: Seabed profile with a 1:100 slope, the black dot shows the location of the OWT and the black dashed lines show the wave generation zone and relaxation zone respectively in the numerical wave tank within OceanWave3D.

A typical storm sea state with 50-year return period in the Northern North Sea located at approximately E3.0 $0^{\circ}$, N58.5 with $100 \mathrm{~m}$ water depth was provided by DHI. As a detailed investigation on storm profiles is not the focus of this study, a generic storm profile taken from NORSOK N-003 (2007) is considered reasonable. This involves three phases: a buildup phase, a peak phase and a decay phase, depicted in Figure 9. The peak phase lasts 3 hours, while the build-up and decay duration are each 18 hours (Tarp-Johansen, 2005). The temporal development of wind speed is assumed to be similar to the trend of wave condition during the storm with a turbulence intensity assumed to be 0.11. The storm profile is discretized into 1 hour sea state. Therefore, 19 sea states are obtained in total, listed in Table 3. The relation between peak wave period $T_{P}$ and significant wave height $H_{S}$ was established by DHI as described in the following equation:

$$
T_{P}=4.38 \sqrt{H_{S}}
$$

The bathymetry shown in Figure 8 was modeled within OceanWave3D in order to capture the nonlinear effects such as re-distribution of the energy between free and bound components in the nonlinear wave realization as well as wave transformation along the sloping seabed (Schløer et al., 2016).

Linear irregular waves from a Jonswap spectrum are generated in $100 \mathrm{~m}$ water depth within the $1000 \mathrm{~m}$ wave generation zone and assumed as uni-directional to simplify the 


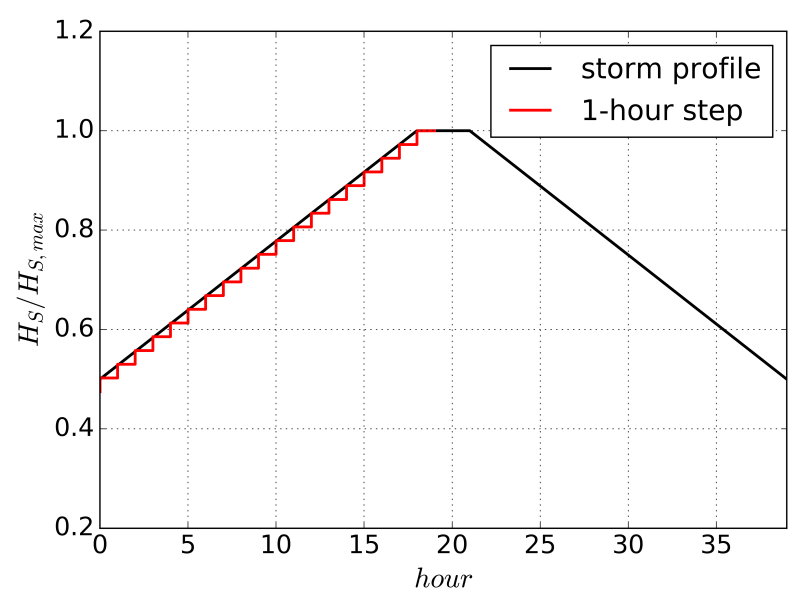

Figure 9: Temporal development of a generic storm profile with 1-hour discretization (NORSOK N-003. 2007).

problem as two dimensional. At the end of the fluid domain, a wave relaxation zone is defined where waves are damped out numerically. The length of wave relaxation zone is identical with wave generation zone, depicted in Figure 8. The OWT location is also shown as a black dot in $33 \mathrm{~m}$ water depth.

Based on the convergence study performed by Schløer et al. (2016), at least 10 points underneath wave surface and at least 8 points per wave length are necessary to ensure all waves of interest are resolved properly using OceanWave3D. The energy spectrum shown in the sea states is approximately bounded between $0.05-0.30 \mathrm{~Hz}$. The shortest wave component with the frequency of $0.30 \mathrm{~Hz}$ has the wave length of $L=17.3 \mathrm{~m}$ in $33 \mathrm{~m}$ water depth based on linear dispersion relation and therefore the grid spacing is set as $1.5 \mathrm{~m}$ in the $x$-direction. In addition, 10 points are resolved underneath the wave surface elevation.

The transition time for these waves to travel from the wave generation zone to the investigated location is decided by travel distance and wave group velocity. The slowest wave with the frequency of $0.30 \mathrm{~Hz}$ has a group velocity as $V_{g}=2.6 \mathrm{~m} / \mathrm{s}$, thus it takes approximately $4000 \mathrm{~s}$ to reach the location in $33 \mathrm{~m}$ water depth. In order to ensure that all the interested wave components in the energy spectrum are captured at the investigated location, the transition time is set as $4400 \mathrm{~s}$, shown in Figure 10.

Regarding nonlinear wave realizations, waves move from $h=100 \mathrm{~m}$ to $h=33 \mathrm{~m}$ following the shoaling process by which waves entering shallower water change in wave height. Specifically, the significant wave height $H_{S}$ in the investigated water depth $h=33 \mathrm{~m}$ is reduced, listed in Table 3. It is consistent with the findings of Schløer et al. (2016). The significant wave heights $H_{S}$ in $h=33 \mathrm{~m}$ were then used to generate linear irregular waves in order to ensure that the obtained wave kinematics from linear and nonlinear waves have the same $H_{S}$ and $T_{P}$ values. 
Table 3: Metocean data of 19 sea states in a generic storm ( $w s p$ : mean wind speed; $H_{S, 100}$ : significant wave height in $100 \mathrm{~m}$ water depth; $H_{S, 33}$ : significant wave height in $33 \mathrm{~m}$ water depth; $T_{P}$ : peak wave period).

\begin{tabular}{cllll}
\hline Sea State & $w s p[\mathrm{~m} / \mathrm{s}]$ & $H_{S, 100}[\mathrm{~m}]$ & $H_{S, 33}[\mathrm{~m}]$ & $T_{P}[\mathrm{~s}]$ \\
\hline 1 & 25.7 & 6.6 & 5.9 & 11.3 \\
2 & 27.1 & 7.0 & 6.2 & 11.6 \\
3 & 28.5 & 7.3 & 6.5 & 11.9 \\
4 & 29.9 & 7.7 & 7.0 & 12.2 \\
5 & 31.3 & 8.1 & 7.4 & 12.5 \\
6 & 32.6 & 8.5 & 7.8 & 12.7 \\
7 & 34.0 & 8.8 & 8.1 & 13.0 \\
8 & 35.4 & 9.2 & 8.4 & 13.3 \\
9 & 36.8 & 9.6 & 8.8 & 13.5 \\
10 & 38.2 & 9.9 & 9.1 & 13.8 \\
11 & 39.6 & 10.3 & 9.4 & 14.1 \\
12 & 41.0 & 10.7 & 9.8 & 14.3 \\
13 & 42.4 & 11.0 & 10.1 & 14.6 \\
14 & 43.8 & 11.4 & 10.4 & 14.8 \\
15 & 45.1 & 11.8 & 10.8 & 15.0 \\
16 & 46.5 & 12.2 & 11.1 & 15.3 \\
17 & 47.9 & 12.5 & 11.4 & 15.5 \\
18 & 49.3 & 12.9 & 11.7 & 15.7 \\
19 & 50.0 & 13.2 & 12.0 & 15.9 \\
\hline
\end{tabular}

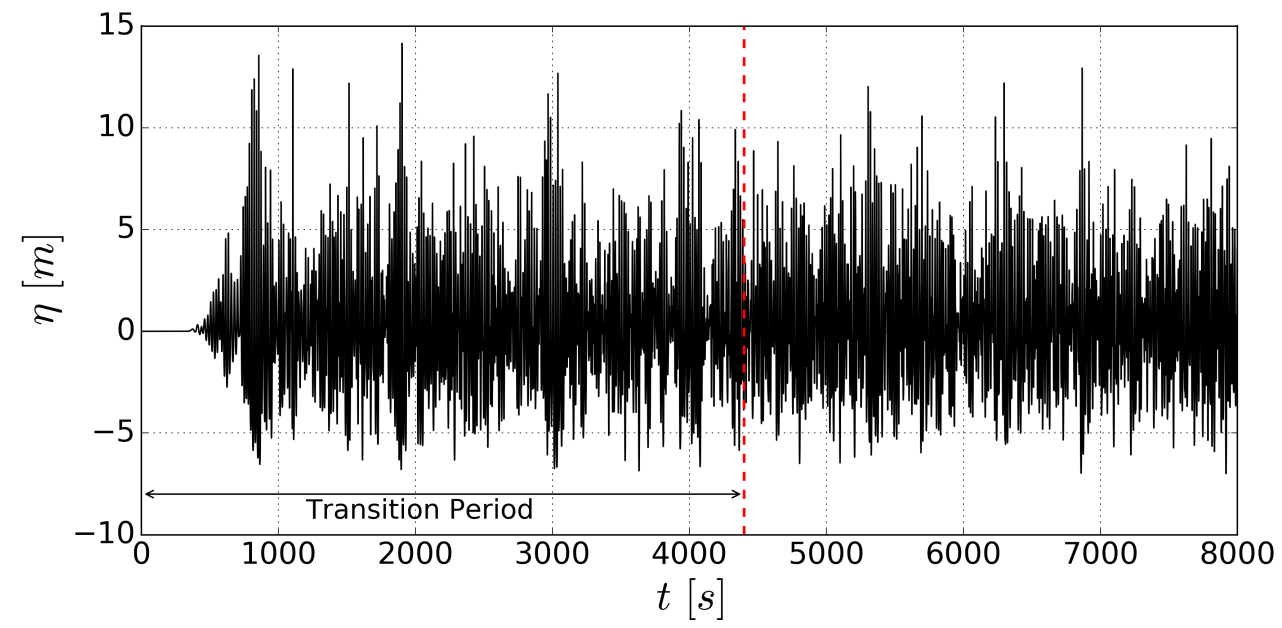

Figure 10: The nonlinear wave surface elevation for the severest sea state $H_{S}=12.0 \mathrm{~m}, T_{P}=15.9 \mathrm{~s}$. The transition period is $4400 \mathrm{~s}$ and in total $8000 \mathrm{~s}$ is required for the simulation. 


\subsection{Geological condition and static soil response}

It is challenging to obtain the geological data considering the requirement of site investigation with expensive cost. A first reasonable estimation for the uppermost layers is loose to medium dense sand in the North Sea (Arany et al., 2017). The loose to medium sand in the upper layers used in this paper has a submerged unit weight of $\gamma^{\prime}=9 \mathrm{kN} / \mathrm{m}^{3}$ and friction angle of $\phi^{\prime}=35^{\circ}$. The geological data for sand are summarized in Table 4 . In the absence of site-specific information, the nonlinear $p-y$ curves recommended in API (2007) and DNV (2014) are used to establish soil resistance in the lateral direction. The soil resistance is assumed to increase linearly with depth.

Table 4: Geological parameters and $p-y$ curve coefficients of sand recommended by API (2007).

\begin{tabular}{llll}
\hline Parameter & Symbol & Value & Unit \\
\hline Submerged unit weight & $\gamma^{\prime}$ & 9 & $\mathrm{kN} / \mathrm{m}^{3}$ \\
Angle of internal friction & $\phi^{\prime}$ & 35 & $\mathrm{deg}$ \\
Relative density & $R_{d}$ & 38 & $\%$ \\
Lateral resistance coefficient & $C_{1}$ & 2.8 & - \\
Lateral resistance coefficient & $C_{2}$ & 3.4 & - \\
Lateral resistance coefficient & $C_{3}$ & 52.8 & - \\
Sand density coefficient & $A_{s}$ & 900 & - \\
Initial modulus of subgrade reaction & $k$ & 6000 & $\mathrm{kN} / \mathrm{m}^{3}$ \\
\hline
\end{tabular}

Static pile moment rotation relation is the starting point for its accumulation analysis subject to cyclic loading, which can be established by either a static load test in experiments (LeBlanc et al., 2010b) or using finite element analysis (Achmus et al., 2009). In this study, HAWC2 was applied by setting up the pile supported with distributed $p-y$ curves of sand, shown in Figure 11(a). For the DTU 10MW wind turbine supported by a large diameter pile with three embedded length $L_{e m}=30,35,40 \mathrm{~m}$, pile diameter $D=7.5 \mathrm{~m}$ and pile wall thickness $t_{p}=0.085 \mathrm{~m}$, the embedded pile behaves in a rigid manner without significant flexibility. The rigid pile behavior is described as a "toe kick" under simultaneous lateral load $H$ and bending moment $M$ (LeBlanc et al., 2010b). Because $H$ and $M$ are not perfectly correlated, there is no precise way of linking rotation $\theta$ to a simultaneous pair of $(H, M)$. Therefore, the combined pair of loads $(H, M)$ is represented by a single loading $M$ or $H$ with the relation $M=H \cdot e$, where $e$ is called load eccentricity. A constant load eccentricity, the average correlation coefficient between mudline moment $M$ and horizontal force $H$, was used as a simplification. The eccentricity was determined to be $25 \mathrm{~m}$, shown in Figure 11(b). The pile moment rotation relations were then established by static load tests with increasing load level $H$ acting on the pile with a value of $25 \mathrm{~m}$ for eccentricity, depicted in Figure 12 . The initial stiffness is also demonstrated, which can be determined via the following equation 
(Darvishi-Alamouti et al., 2017):

$$
\theta=\frac{24 L_{e m}+36 e}{k L_{e m}^{4} e} M
$$

where $L_{e m}$ is pile embedded length, $e$ is load eccentricity, and $k$ is the initial modulus of subgrade reaction. Detailed derivation of the initial stiffness is given in the Appendix. The initial stiffness is normally used to determine the natural frequency of OWTs.

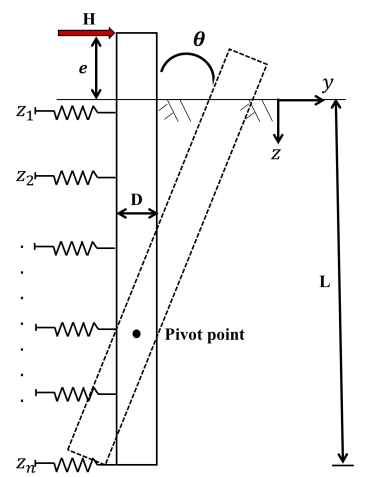

(a)

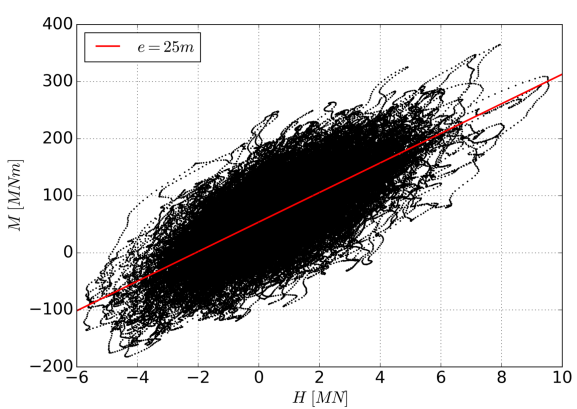

$(\boldsymbol{b})$

Figure 11: (a) Lateral loaded rigid pile with distributed $p-y$ curves modeled in HAWC2. (b) Determination of eccentricity using the average relation between mudline moment $M$ and horizontal force $H$.

It is remarkable that a clear point of sand failure could not be established from the tests to determine the ultimate soil capacity. Here, the definition from LeBlanc et al. (2010b) is used, that the ultimate soil capacity is the bending moment causing $4^{\circ}$ rotation. It shows that a slightly larger embedded length gives a significantly higher ultimate soil capacity.

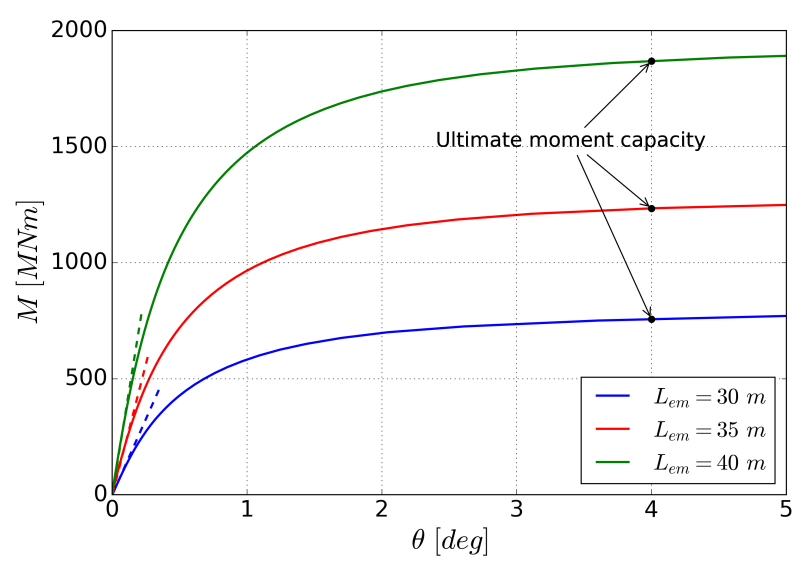

Figure 12: Static moment rotation relations established using HAWC2 $\left(L_{e m}=30 / 35 / 40 \mathrm{~m}, D=7.5 \mathrm{~m}\right.$, $e=25 \mathrm{~m})$. 


\section{Results and discussion}

\subsection{Linear and nonlinear wave realizations}

Wave skewness is used to quantify the departure from Gaussianity to compare the difference between linear and nonlinear wave realizations. The wave with higher peaked crest and rounded trough will be displayed by a positive skewness. Positive skewness obtained from nonlinear waves are stated in Table 5, denoting that nonlinear surface elevation has crest values larger than trough values. The skewness is around zero for all linear wave realizations, indicating a Gaussian distribution for linear wave surface elevation. Besides, the skewness of nonlinear wave realizations increases with more severe sea states. An exemplary time series of linear and nonlinear wave realizations is depicted in Figure 13, where higher peaked crest and rounded trough are noticeable in the nonlinear wave elevation.

Table 5: Wave skewness of the 19 sea states in the storm.

\begin{tabular}{cllllllllll}
\hline Sea State & 1 & 2 & 3 & 4 & 5 & 6 & 7 & 8 & 9 & 10 \\
\hline Linear & 0.01 & -0.02 & -0.07 & 0.00 & 0.00 & 0.02 & -0.01 & -0.01 & 0.01 & -0.01 \\
Nonlinear & 0.19 & 0.14 & 0.19 & 0.22 & 0.23 & 0.17 & 0.23 & 0.24 & 0.23 & 0.23 \\
\hline Sea State & 11 & 12 & 13 & 14 & 15 & 16 & 17 & 18 & 19 & \\
\hline Linear & 0.01 & -0.01 & 0.01 & -0.01 & 0.00 & -0.10 & 0.14 & -0.02 & 0.09 & \\
Nonlinear & 0.28 & 0.28 & 0.30 & 0.34 & 0.38 & 0.39 & 0.42 & 0.42 & 0.42 & \\
\hline
\end{tabular}

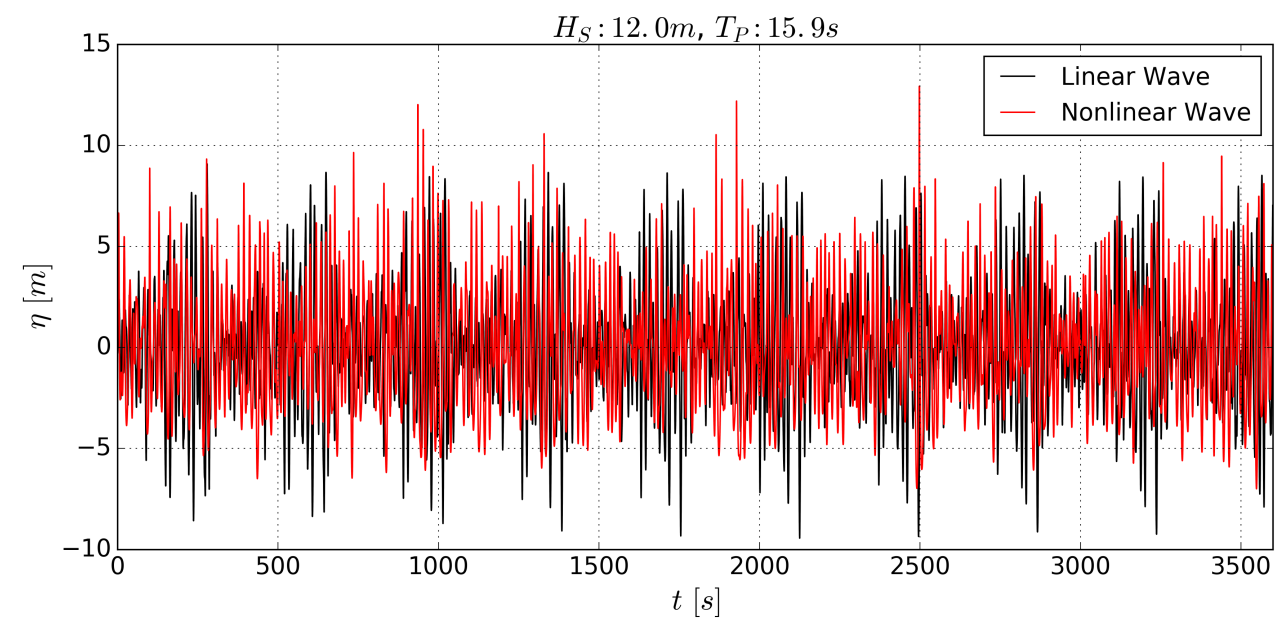

Figure 13: Comparison of the linear and nonlinear wave realizations of the most severe sea state $H_{S}=12.0$ $\mathrm{m}$ and $T_{P}=15.9 \mathrm{~s}$.

Alternatively, the amplitude spectrum of surface elevation was calculated to further understand the influence of wave nonlinearity. The amplitude spectral densities of three 
representative sea states are depicted in Figure 14. They are intended to represent the relatively small, medium and large sea states studied in this paper. The spectrum of nonlinear wave shows a secondary peak at around twice of the peak wave frequency and another small peak close to zero frequency. Such a redistribution of energy arises due to sum and difference interactions of frequencies from nonlinear wave transformation. The phenomenon is more pronounced with severe sea states.
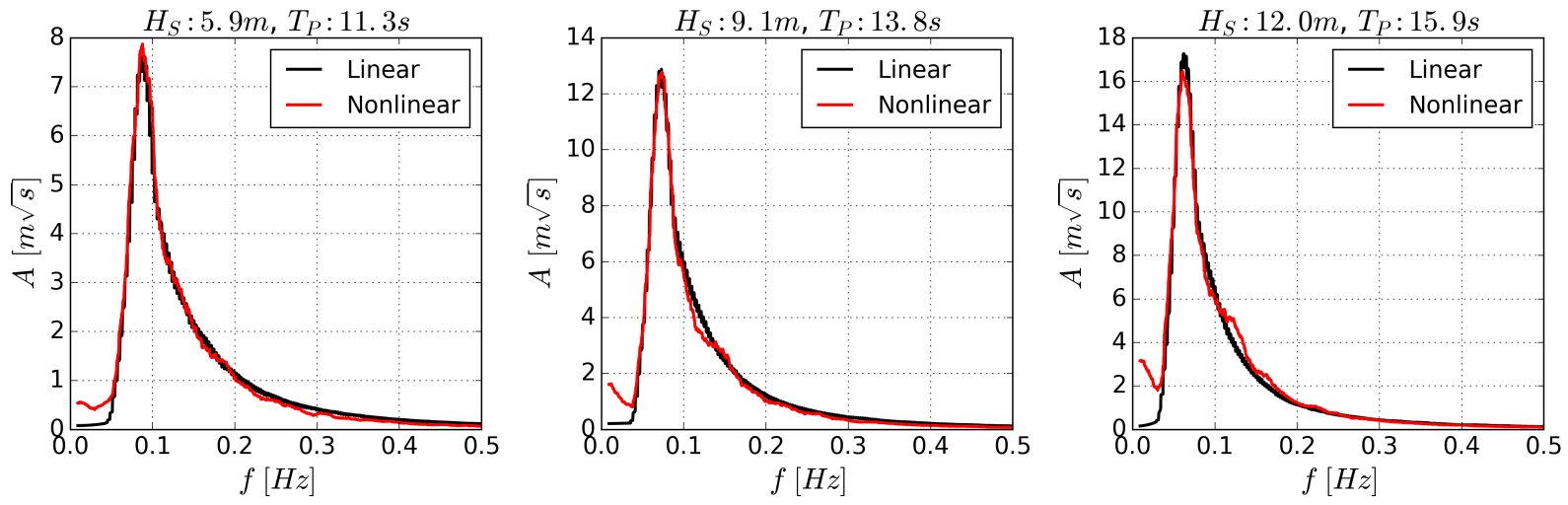

Figure 14: Amplitude spectral density of wave surface elevation for the linear and nonlinear waves of three representative sea states.

\subsection{Aero-elastic simulation results}

In order to investigate the wave forces independent from the dynamic properties of the OWT structures, a fixed monopile was firstly considered to evaluate the loading differences between using linear and nonlinear waves together with the Morison equation. For the purpose of linking the wave elevation and its corresponding loading, exceedance probabilities of the peak values of wave elevation $\eta$, horizontal force $H$ and mudline moment $M$ are calculated using Eq. 25.

$$
P\left(x_{i}\right)=1-\frac{i-1}{N}
$$

where $x_{i}$ is the $i$ th peak value of $\eta, H, M$ identified using zero down-crossing method and sorted in increasing order. $N$ is the number of peak values.

Figure 15 presents the exceedance probabilities of the peak values of $\eta, H, M$ when linear and nonlinear waves are used for the three representative sea states. The probability plot shows that using the nonlinear wave realizations gives higher peak values of $\eta, H, M$ at rare probability level compared to those predicted for the linear waves, and their trends are similar. The deviation between the linear and nonlinear waves becomes more notable in more severe sea states.

Afterwards, the simultaneous aerodynamic loads and hydrodynamic loads were taken into account in the aero-elastic simulations. Figure 16 shows the amplitude spectral density of fore-aft mudline moment using the linear and nonlinear waves. The spectrum has a significant peak at around $0.22 \mathrm{~Hz}$, which is the natural frequency of the first bending mode 

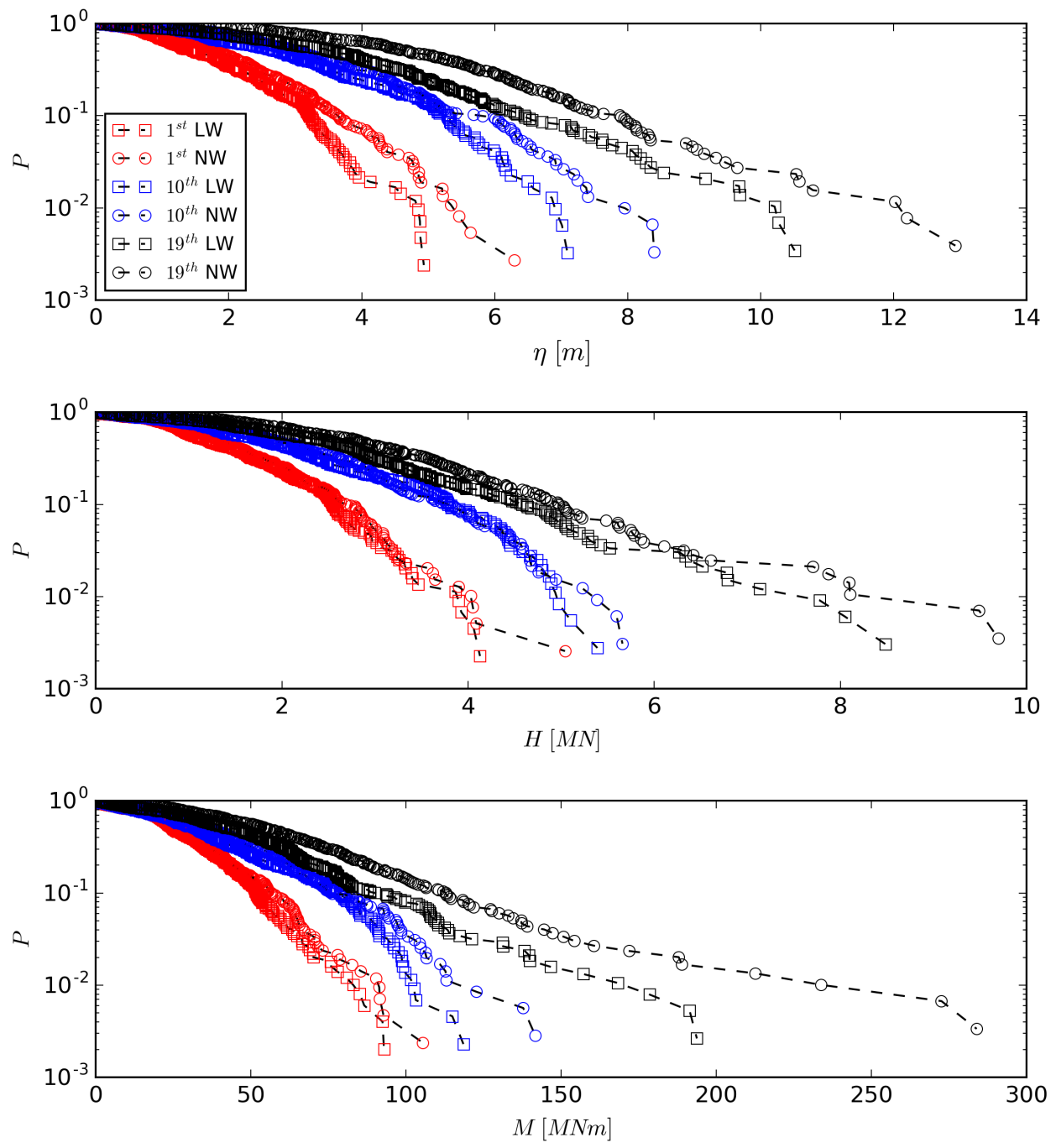

Figure 15: The exceedance probability of the peak values for $\eta, H, M$ using the linear and nonlinear waves of three representative sea states $\left(1^{s t}-H_{S}: 5.9 m, T_{P}: 11.3 s ; 10^{t h}-H_{S}: 9.1 m, T_{P}: 13.8 s ; 19^{s t}-H_{S}:\right.$ $12.0 m, T_{P}: 15.9 s ;$ LW-linear wave, NW-nonlinear wave).

of tower in the fore-aft direction. The peak is pronounced due to poor suppression as a result of low aerodynamic damping value with parked rotor. Another significant peak is seen at around the peak wave frequency showing a quasi-static behavior subjected to hydrodynamic force. The small peak at around twice the peak wave frequency also shows in the plots.

\subsection{Permanent accumulated rotation}

As stated earlier, the highly irregular loading series obtained from aero-hydro-elastic simulations need to be transformed into a set of load parcels using the rainflow counting method. Figure 17 shows the histogram of load magnitude for all the load parcels transformed from the mudline moment series during the storm. Almost identical numbers of cycles are found 

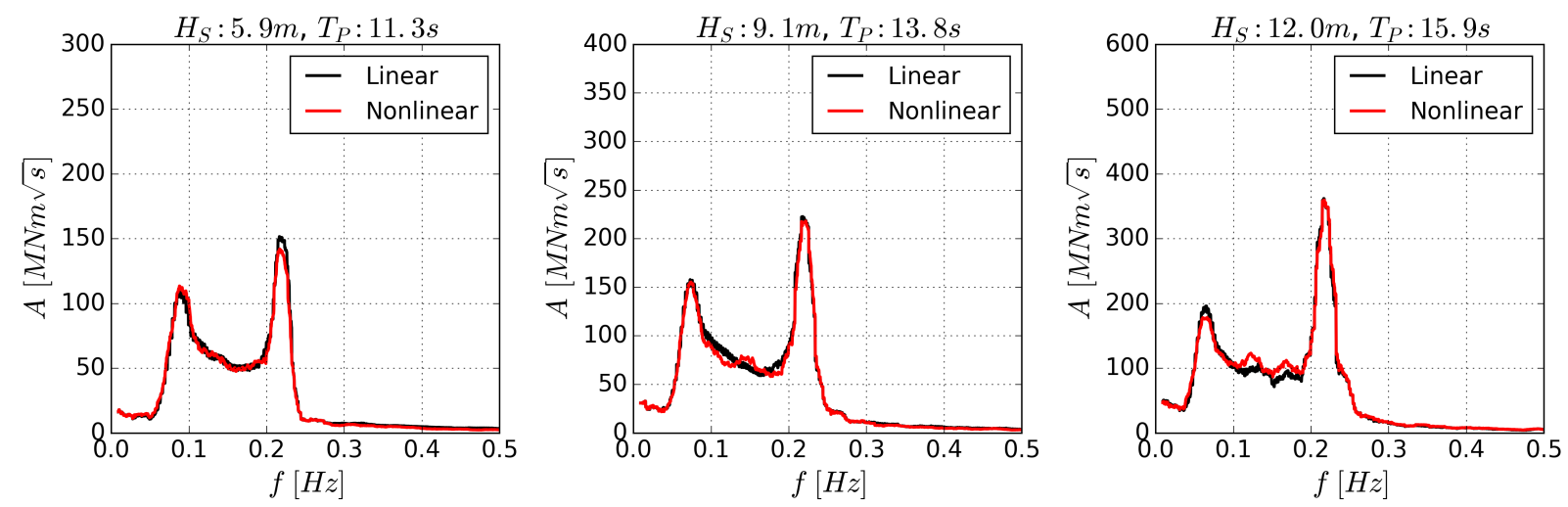

Figure 16: Amplitude spectral density of the mudline moment using the linear and nonlinear waves of three representative sea states.

for the load parcels with small loading magnitude as a result of the dominating structural vibration in its first tower bending natural frequency. More cycles, nevertheless, are obtained for the load parcels with large loading magnitude when the nonlinear waves are used. This phenomenon is consistent with the exceedance probability of hydrodynamic force acting on the structure, shown in Figure 15. The cyclically accumulated rotations are calculated for each load parcel and depicted in Figure 17 for the embedded pile of $L_{e m}=35 \mathrm{~m}$. The results agree with the conclusion from LeBlanc et al. (2010a) that the largest load cycles, although very few in number, generate higher accumulated rotation than the thousands of small load cycles. This behavior is also valid for the monopile with $L_{e m}$ as 30 and $40 \mathrm{~m}$. It indicates that the number of loading cycles has a relatively small effect on the accumulated rotation compared to the effect from load characteristics.

The accumulation of permanent rotation during the 39-hour storm was calculated based on Miner's rule, depicted in Figure 18. In general, less rotation is accumulated for a longer pile which has more ultimate moment capacity. Moreover, using linear waves slightly underestimates the permanent accumulated rotation. It also shows that the build-up of permanent accumulated rotation becomes slower due to pre-accumulated rotation. This is because the surrounding soils are typically densified as a result of the cyclic pre-loading. These results demonstrate that the accumulated rotation primarily depends on the soil capacity, loading characteristics and pre-loading history.

Table 6lists the permanent accumulated rotation for the three embedded lengths studied. Static pushover analysis was also performed so that the rotation was calculated directly from the static moment rotation relation subject to the largest moment in the load series. The values calculated using cyclic analysis are significantly larger than these from static analysis. Regarding nonlinear waves, $67 \%-195 \%$ more rotation is predicted using cyclic analysis compared to static analysis. It is also seen that $6 \%-10 \%$ more rotation is predicted when nonlinear waves are used for cyclic analysis. 

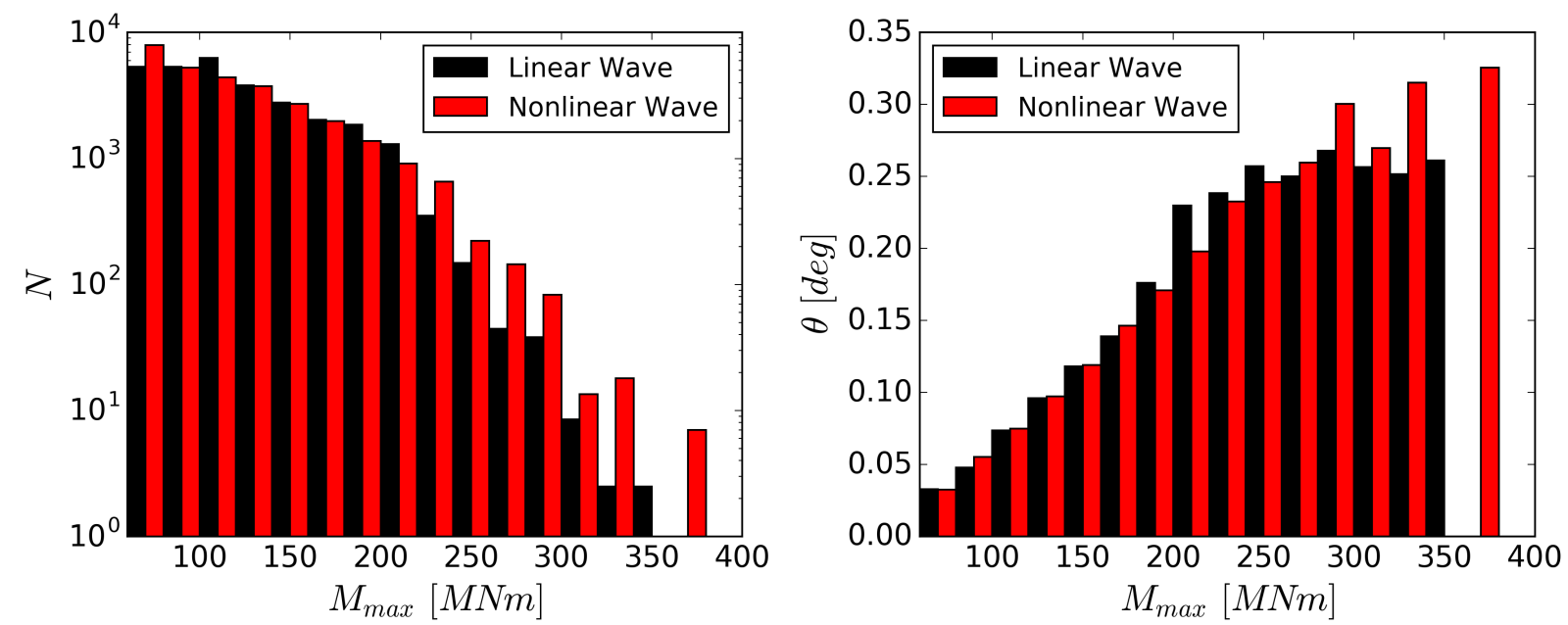

Figure 17: The histogram of load magnitude $M_{\max }$ for all the load parcels transformed from the mudline moment series during the storm and its corresponding cyclically accumulated rotation for monopile with $L_{e m}=35 \mathrm{~m}$.

Table 6: Permanent accumulated rotation calculated using static pushover and cyclic analysis.

\begin{tabular}{lccc}
\hline $\boldsymbol{L}_{\boldsymbol{e m}}=\mathbf{3 0 m}$ & Static [deg] & Cyclic [deg] & Ratio \\
\hline Linear & 0.409 & 1.125 & $\mathbf{2 . 7 5}$ \\
Nonlinear & 0.422 & 1.243 & $\mathbf{2 . 9 5}$ \\
Ratio & $\mathbf{1 . 0 3}$ & $\mathbf{1 . 1 0}$ & \\
\hline $\boldsymbol{L}_{\boldsymbol{e m}}=\mathbf{3 5 m}$ & Static $[\mathrm{deg}]$ & Cyclic [deg] & Ratio \\
\hline Linear & 0.195 & 0.399 & $\mathbf{2 . 0 5}$ \\
Nonlinear & 0.200 & 0.432 & $\mathbf{2 . 1 6}$ \\
Ratio & $\mathbf{1 . 0 3}$ & $\mathbf{1 . 0 8}$ & \\
\hline $\boldsymbol{L}_{\boldsymbol{e m}}=\mathbf{4 0 m}$ & Static $[\mathrm{deg}]$ & Cyclic [deg] & Ratio \\
\hline Linear & 0.114 & 0.181 & $\mathbf{1 . 5 9}$ \\
Nonlinear & 0.116 & 0.194 & $\mathbf{1 . 6 7}$ \\
Ratio & $\mathbf{1 . 0 2}$ & $\mathbf{1 . 0 6}$ & \\
\hline
\end{tabular}

\subsection{Discussion on practical implications for design}

Although for practical design full scale validation is required, the research findings from the case study can reflect some practical implications for future design approaches. The current $p-y$ approach with a constant reduction factor to account for the cyclic effect is clearly shown not represent the rotation accumulation process. Alternatively, the explicit methodology presented in this paper based on the model proposed by LeBlanc et al. (2010b) and Miner's rule-based superposition shows the potential suitability for the early stages of the design process. The permanent accumulated rotation of an OWT is found to be sensitive to the embedded pile length, hereby the pile geometry should be carefully selected by the 


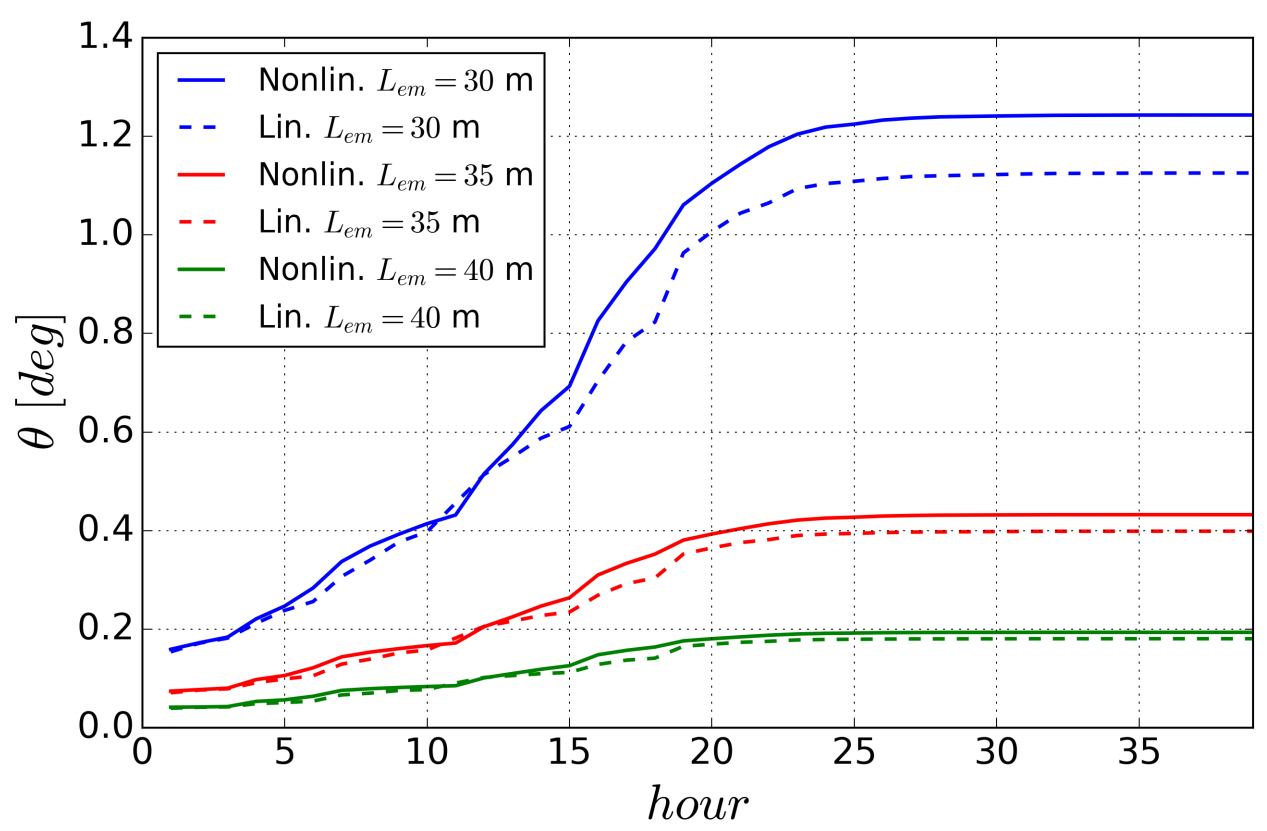

Figure 18: Accumulation of the permanent rotation during the 39-hour storm using linear waves and nonlinear waves for $L_{e m}=30,35,40 \mathrm{~m}$.

designer to fulfill the SLS requirements. Additionally, the results show that investigation of the storm peak condition should be sufficient for preliminary design because all largest load cycles present in this period. Furthermore, wave nonlinearity has only limited influence on OWT permanent accumulated rotation, hereby it should be sufficient to use linear waves in the permanent rotation analysis. The design procedure should be iterated in order to find a safe, but less conservative design.

\section{Conclusions}

According to DNV (2014), prediction of permanent accumulated rotation of the pile head, at least for a single storm, is typically critical in terms of fulfilling the requirement for SLS. In this paper, we present a workflow to predict the permanent accumulated rotation in a storm by including the effect from fully nonlinear irregular waves versus commonly used linear wave theory. The DTU 10MW wind turbine sited in $33 \mathrm{~m}$ water depth with three embedded lengths below seabed as 30,35 and $40 \mathrm{~m}$ in sand was investigated.

Regarding the analysis for wave realizations, the nonlinear waves realized from OceanWave3D tend to be more non-Gaussian causing wave crests to be sharper and wave troughs flatter. The corresponding extreme wave forces due to nonlinear waves are predicted to be larger than those calculated from linear waves based on the Morison equation.

The aero-elastic simulations of wind turbine response were performed using HAWC2 for 19 1-hour sea states, using both linear and fully nonlinear wave models. The dynamic response is dominated by the first bending mode of tower in the fore-aft direction due to 
low aerodynamic damping value with parked rotor. Moreover, the monopile responds to the wave force in a relatively quasi-static manner. Following this, the rainflow counting method was used to rearrange the highly irregular load series into a set of so-called load parcel, a $N$ cycles constant-amplitude load series bounded by the maximum and minimum moment. The number of cycles for the load parcels with small loading magnitude is found out to be almost identical. However, a few more cycles are obtained for the load parcels with extremely large loading magnitude when the nonlinear waves are used.

The method proposed by LeBlanc et al. (2010b) with Miner's rule was used to predict the cyclically accumulated rotation during the storm. The extremely large load cycles, although very few in number, generate higher accumulated rotation than the thousands of small load cycles. Furthermore, the analysis shows that the cyclically accumulated rotation is significantly higher than the value predicted from static analysis. The results show that the accumulated rotation primarily depends on the soil capacity, the pre-loading history and loading characteristics. Ultimately, this study suggests that nonlinear irregular waves have only limited influence on the permanent accumulated rotation.

\section{Acknowledgement}

This study is a part of the project DeRisk (Grant Number 4106-00038B), which is funded by Innovation Fund Denmark. Further funding is provided by Equinor and the participating partners. All funding is gratefully acknowledged. Henrik Bredmose at DTU Wind Energy is greatly appreciated for guiding OceanWave3D.

\section{Appendix}

The subgrade modulus in sand is expressed mathematically as $k z$, where $k$ is the initial modulus of subgrade reaction and $z$ is soil depth. The unit soil reaction forces at each soil layer above pivot point and below it, denoted as $d F_{1}$ and $d F_{2}$ respectively, can therefore be calculated as:

$$
\begin{cases}d F_{1}(z)=k z \cdot\left(\lambda L_{e m}-z\right) \theta=k z\left(\lambda L_{e m}-z\right) \theta & 0 \leq z \leq \lambda L_{e m} \\ d F_{2}(z)=k z \cdot\left(z-\lambda L_{e m}\right) \theta=k z\left(z-\lambda L_{e m}\right) \theta & \lambda L_{e m}<z \leq L_{e m}\end{cases}
$$

where $\lambda$ is used to determine the ratio of length above pivot point to the total embedded length. The total soil reaction forces can be derived as:

$$
\begin{gathered}
F_{1}=\int_{0}^{\lambda L_{e m}} d F_{1}(z) d z=\int_{0}^{\lambda L_{e m}} k z\left(\lambda L_{e m}-z\right) \theta d z=\frac{k \theta L_{e m}^{3} \lambda^{3}}{6} \\
F_{2}=\int_{\lambda L_{e m}}^{L_{e m}} d F_{2}(z) d z=\int_{\lambda L_{e m}}^{L_{e m}} k z\left(z-\lambda L_{e m}\right) \theta d z=\frac{k \theta L_{e m}^{3}\left(2-3 \lambda+\lambda^{3}\right)}{6}
\end{gathered}
$$

The resultant moments of soil reaction around the ground point at pile head are calculated by:

$$
M_{1}=\int_{0}^{\lambda L_{e m}} d F_{1}(z) z d z=\int_{0}^{\lambda L_{e m}} k z^{2}\left(\lambda L_{e m}-z\right) \theta d z=\frac{k \theta L_{e m}^{4} \lambda^{4}}{12}
$$




$$
M_{2}=\int_{\lambda L_{e m}}^{L_{e m}} d F_{2}(z) z d z=\int_{\lambda L_{e m}}^{L_{e m}} k z^{2}\left(z-\lambda L_{e m}\right) \theta d z=\frac{k \theta L_{e m}^{4}\left(3-4 \lambda+\lambda^{4}\right)}{12}
$$

$\theta$ and $\lambda$ are obtained using the force and moment equilibrium equations:

$$
\begin{gathered}
\sum F=0 \Rightarrow H+F_{2}-F_{1}=H+\frac{k \theta L_{e m}^{3}(2-3 \lambda)}{6}=0 \\
\sum M=0 \Rightarrow M+M_{1}-M_{2}=M+\frac{k \theta L_{e m}^{4}(4 \lambda-3)}{12}=0
\end{gathered}
$$

replacing $H$ with $\frac{M}{e}$ and substituting Eq. (31) into Eq. 32 yield:

$$
\begin{gathered}
\theta=\frac{24 L_{e m}+36 e}{k L_{e m}^{4} e} M \\
\lambda=\frac{3 L_{e m}+4 e}{4 L_{e m}+6 e}
\end{gathered}
$$

It is noted that the moment-rotation relation is linear for a rigid pile. The derived Eq. (33) and Eq. (34) are identical with what derived by Darvishi-Alamouti et al. (2017).

\section{References}

Abadie, C. N. (2015). Cyclic lateral loading of monopile foundations in cohesionless soils. Ph.D. thesis University of Oxford.

Achmus, M., Albiker, J., \& Abdel-Rahman, K. (2010). Investigations on the behavior of large diameter piles under cyclic lateral loading. In Proc., 2nd Int. Symposium Frontiers in Offshore Geotechnics (ISFOG) (pp. 471-476). Taylor \& Francis London, UK.

Achmus, M., Kuo, Y. S., \& Abdel-Rahman, K. (2009). Behavior of monopile foundations under cyclic lateral load. Computers and Geotechnics, 36, 725-735. doi:10.1016/j.compgeo.2008.12.003.

Agarwal, P., \& Manuel, L. (2011). Incorporating irregular nonlinear waves in coupled simulation and

reliability stuci

Allotey, N., \& El Naggar, M. H. (2008). Generalized dynamic Winkler model for nonlinear soil-structure interaction analysis. Canadian Geotechnical Journal, 45, 560-573. doi:10.1139/T07-106.

Andersen, K. H. (2015). Cyclic soil parameters for offshore foundation design Main goals. The Third ISSMGE McClelland Lecture,

API (2007). Recommended Practice for Planning, Designing and Constructing Fixed Offshore Platforms Working Stress Design. Api Recommended Practice, 24-WSD, 242. doi:10.1007/s13398-014-0173-7.2.

Arany, L., Bhattacharya, S., Macdonald, J., \& Hogan, S. J. (2017). Design of monopiles for offshore wind turbines in 10 steps. Soil Dynamics and Earthquake Engineering, 92, 126-152. doi:10.1016/j.soildyn. 2016.09.024

Bak, C., Zahle, F., Bitsche, R., Yde, A., Henriksen, L. C., Nata, A., \& Hansen, M. H. (2013). Description of the DTU 10 MW Reference Wind Turbine. DTU Wind Energy Report-I-0092, (pp. 1-138).

Barari, A., Bagheri, M., Rouainia, M., \& Ibsen, L. B. (2017). Deformation mechanisms for offshore monopile foundations accounting for cyclic mobility effects. Soil Dynamics and Earthquake Engineering, 97, 439453. doi $10.1016 / j$.soildyn.2017.03.008. 
Bhattacharya, S., Cox, J. A., Lombardi, D., \& Muir Wood, D. (2013). Dynamics of offshore wind turbines supported on two foundations. Proceedings of the Institution of Civil Engineers - Geotechnical Engineering, 166, 159-169. doi:10.1680/geng.11.00015.

Bhattacharya, S., Nikitas, G., Arany, L., \& Nikitas, N. (2012). Soil Structure Interactions for Offshore Wind Turbines. Engineering \& Technology Reference, 1. doi:10.1049/etr.2016.0019.

Byrne, B., \& Houlsby, G. (2003). Foundations for offshore wind turbines. Philosophical Transactions of the Royal Society of London A: Mathematical, Physical and Engineering Sciences, 361, 2909-2930. doi 10.1098/rsta.2003.1286.

Carswell, W., Arwade, S., DeGroot, D., \& Myers, A. (2016). Natural frequency degradation and permanent accumulated rotation for offshore wind turbine monopiles in clay. Renewable Energy, 97, 319-330. doi $10.1016 /$ j.renene.2016.05.080.

Corciulo, S., Zanoli, O., \& Pisanò, F. (2017). Transient response of offshore wind turbines on monopiles in sand: role of cyclic hydro-mechanical soil behaviour. Computers and Geotechnics, 83, 221-238. doi $10.1016 /$ j.compgeo.2016.11.010.

Cuéllar, P., Mira, P., Pastor, M., Merodo, J. A. F., Baeßler, M., \& Rücker, W. (2014). A numerical model for the transient analysis of offshore foundations under cyclic loading. Computers and Geotechnics, 59, 75-86. doi:10.1016/j.compgeo.2014.02.005

Damgaard, M., Zania, V., Andersen, L. V., \& Ibsen, L. B. (2014). Effects of soil-structure interaction on real time dynamic response of offshore wind turbines on monopiles. Engineering Structures, 75, 388-401. doi $10.1016 / j$.engstruct.2014.06.006.

Darvishi-Alamouti, S., Bahaari, M. R., \& Moradi, M. (2017). Natural frequency of offshore wind turbines on rigid and flexible monopiles in cohesionless soils with linear stiffness distribution. Applied Ocean Research, 68, 91-102. doi $10.1016 / \mathrm{j}$.apor.2017.07.009

DNV (2014). DNV-OS-J101 Design of Offshore Wind Turbine Structures. May, (pp. 212-214).

Engsig-Karup, A. P., Bingham, H. B., \& Lindberg, O. (2009). An efficient flexible-order model for 3D nonlinear water waves. Journal of Computational Physics, 228, 2100-2118. doi:10.1016/j.jcp.2008. 11.028 .

Hasselmann, K., Barnett, T., Bouws, E., Carlson, H., Cartwright, D., Enke, K., Ewing, J., Gienapp, H., Hasselmann, D., Kruseman, P. et al. (1973). Measurements of wind-wave growth and swell decay during the joint north sea wave project (jonswap). Ergänzungsheft 8-12, .

Hettler, A. (1981). Verschiebungen starrer und elastischer Gründungskörper in Sand bei monotoner und zyklischer Belastung volume 90. Institut für Bodenmechanik und Felsmechanik der Universität Fridericiana.

Jia, J. (2018). Soil Dynamics and Foundation Modeling. Springer. doi:10.1007/978-3-319-40358-8

Kallehave, D., Byrne, B. W., LeBlanc Thilsted, C., \& Mikkelsen, K. K. (2015). Optimization of monopiles for offshore wind turbines. Philosophical Transactions of the Royal Society A: Mathematical, Physical and Engineering Sciences, 373. doi:10.1098/rsta.2014.0100

Khoa, H. D. V., \& Jostad, H. P. (2017). Application of a cyclic accumulation model udcam to fe analyses of offshore foundations. In Congrès International de Géotechnique-Ouvrages-Structures (pp. 656-667). Springer. doi: $10.1007 / 978-981-10-6713-6 \_65$.

Klinkvort, R. T., \& Hededal, O. (2013). Lateral response of monopile supporting an offshore wind turbine.

Proceedings of the Institution of Civil Engineers - Geotechnical Engineering, 166, 147-158. doi 10.1680/ geng.12.00033

Larsen, T. J., \& Hansen, A. M. (2015). HAWC2, the user's manual. July.

Larsen, T. J., Madsen, H. A., Larsen, G. C., \& Hansen, K. S. (2014). Validation of the dynamic wake meander model for loads and power production in the Egmond aan Zee wind farm. Wind Energy, 17, 657-669. doi $10.1002 / \mathrm{we}$.

LeBlanc, C., Byrne, B., \& Houlsby, G. (2010a). Response of stiff piles to random two-way lateral loading. Géotechnique, 60, 715-721. doi 10.1680/geot.09.T.011.

LeBlanc, C., Houlsby, G., \& Byrne, B. (2010b). Response of stiff piles in sand to long-term cyclic lateral loading. Géotechnique, 60, 79-90. doi:10.1680/geot.7.00196 
Li, W., Igoe, D., \& Gavin, K. (2015). Field tests to investigate the cyclic response of monopiles in sand.

Proceedings of the Institution of Civil Engineers - Geotechnical Engineering, 168, 407-421. doi 10.1680/ jgeen.14.00104.

Lin, S.-S., \& Liao, J.-C. (1999). Permanent strains of piles in sand due to cyclic lateral loads. Journal

of geotechnical and geoenvironmental engineering, 125, 798-802. doi 10.1061/(ASCE) 1090-0241(1999) $125: 9(798)$.

Little, R. L., \& Briaud, J.-L. (1988). Full scale cyclic lateral load tests on six single piles in sand. Technical Report TEXAS A AND M UNIV COLLEGE STATION DEPT OF CIVIL ENGINEERING.

Lombardi, D., Bhattacharya, S., \& Muir Wood, D. (2013). Dynamic soil-structure interaction of monopile supported wind turbines in cohesive soil. Soil Dynamics and Earthquake Engineering, 49, 165-180. doi $10.1016 / j$.soildyn.2013.01.015.

Long, J., \& Vanneste, G. (1994). Effects of cyclic lateral loads on piles in sand. Journal of Geotechnical Engineering, 120, 225-244. doi 10.1061/(ASCE) 0733-9410(1994)120:1(225).

Marino, E., Nguyen, H., Lugni, C., Manuel, L., \& Borri, C. (2015). Irregular Nonlinear Wave Simulation and Associated Loads on Offshore Wind Turbines. Journal of Offshore Mechanics and Arctic Engineering, 137, 021901. doi:10.1115/1.4029212.

Matsuishi, M., \& Endo, T. (1968). Fatigue of metals subjected to varying stress. Proceedings of the Kyushu Branch of Japan Society of Mechanics Engineering, (pp. 37-40).

Niemunis, A., Wichtmann, T., \& Triantafyllidis, T. (2005). A high-cycle accumulation model for sand. Computers and Geotechnics, 32, 245-263. doi 10.1016/j.compgeo.2005.03.002.

NORSOK N-003 (2007). NORSOK: N-003 Actions and action effects. The Norwegian Oil Industry Association (OLF) and Federation of Norwegian Manufacturing Industries (TBL), .

Reese, L. C., Cox, W. R., \& Koop, F. D. (1974). Analysis of laterally loaded piles in sand. Offshore Technology in Civil Engineering Hall of Fame Papers from the Early Years, (pp. 95-105).

Schløer, S., Bredmose, H., \& Bingham, H. B. (2016). The influence of fully nonlinear wave forces on aero-

hydro-elastic calculations of monopile wind turbines. Marine Structures, 50, 162-188. doi:10.1016/j. marstruc.2016.06.004

Tarp-Johansen, N. J. (2005). Partial Safety Factors and Characteristic Values for Combined Extreme Wind and Wave Load Effects. Journal of Solar Energy Engineering, 127, 242. doi:10.1115/1.1862259.

Terzaghi, K. (1955). Evaluation of Coefficient of Subgrade Reaction. Geotechnique, London, 5, 41-50.

Truong, P., Lehane, B., Zania, V., \& Klinkvort, R. T. (2018). Empirical approach based on centrifuge testing for cyclic deformations of laterally loaded piles in sand. Géotechnique, (pp. 1-13). doi 10.1680/ jgeot.17.P.203.

Wang, S., \& Larsen, T. J. (2017). Identification of critical design load cases for a jacket supported offshore wind turbine. In The 27th International Ocean and Polar Engineering Conference. International Society of Offshore and Polar Engineers. doi ISOPE-I-17-325.

Wichtmann, T., \& Triantafyllidis, T. (2017). Strain accumulation due to packages of cycles with varying amplitude and/or average stress - On the bundling of cycles and the loss of the cyclic preloading memory. Soil Dynamics and Earthquake Engineering, 101, 250-263. doi:10.1016/j.soildyn.2017.07.012.

WindEurope (2018). Offshore Wind in Europe - Key trends and statistics 2017, .

Yang, M., Luo, R., \& Li, W. (2018). Numerical study on accumulated deformation of laterally loaded monopiles used by offshore wind turbine. Bulletin of Engineering Geology and the Environment, 77, 911-921. doi 10.1007/s10064-017-1138-9.

Zaaijer, M. B. (2006). Foundation modelling to assess dynamic behaviour of offshore wind turbines. Applied Ocean Research, 28, 45-57. doi:10.1016/j.apor.2006.03.004. 